\title{
EL MALTRATO ANIMAL EN LA PRODUCCIÓN DE ALIMENTOS. ANÁLISIS JURÍDICO-PENAL
}

\author{
Autores: Leaned Matos Hidalgo \\ lmatosh@udg.co.cu \\ Universidad de Granma, Cuba \\ Roisbel Aroche Ginarte \\ rarocheg@udg.co.cu \\ Universidad de Granma, Cuba \\ Alcides Antúnez Sánchez \\ aantunez@udg.co.cu \\ Universidad de Granma, Cuba
}

\section{Resumen}

El trabajo tiene como objetivo fundamental elaborar pautas para el perfeccionamiento de la protección a los animales durante la producción de alimentos desde un punto de vista multidisciplinario, enfocado a los elementos que aporta las Ciencias Veterinarias y las Ciencias Jurídicas, que permita mitigar las acciones antijurídicas concebidas como maltrato y crueldad animal, como una necesidad emergente de la que Cuba como nación no está ajena, teniendo en cuenta que existen limitaciones 
económicas, de procedimiento, técnicas, y por supuesto, en el orden jurídico que trasgreden el bienestar de los animales y que deberían penalizarse, influyendo en muchos casos en la producción final de alimentos para la población; aspecto que constituye prioridad en la actual coyuntura social por la que atraviesa el país.

Palabras clave: bienestar animal; maltrato animal; producción de alimentos; función inspectora; análisis jurídico criminal.

\title{
The animal mistreatment in the production of foodstuff. Juridical criminal analysis
}

\begin{abstract}
The work has like fundamental objective to elaborate guidelines for the perfecting of the protection to the animals during the production of foodstuff from one point of multi-disciplinary sight, focused to the elements that contribute Sciences Veterinarians and the Juridical Sciences, that it allows mitigating the unlawful actions conceived like mistreatment and animal cruelty, like an emerging need of which Cuba nationally is not our own, considering that cost-reducing, procedure limitations, techniques exist, and of course, in the jurisprudence than violates the well-being of the animals that should be penalized and, influencing in many instances the final production of foodstuff for the population; aspect that constitutes priority in the present juncture that cross the country for.
\end{abstract}

Key words: animal well-being; animal mistreatment; production of foodstuff; show inspective; Juridical criminal analysis.

Fecha de recepción: 25/10/2019.

Fecha de aceptación: 02/12/2019.

\section{INTRODUCCIÓN}

En el último cuarto del siglo pasado, las concepciones de los animales no humanos en general y de los de compañía en particular, han cambiado sustancialmente, existe una demanda social reivindicando respeto y derechos para los animales no humanos. Es por ello que desde la Veterinaria se ha establecido un decálogo de bienestar animal en la producción de alimentos, que permita que los índices de producción aumenten y se respeten los derechos de los animales, aspectos que indudablemente trascienden a la esfera del Derecho, para lo cual es necesario identificar la relación entre el Derecho Animal y el Derecho Ambiental y si es 
posible considerar al Derecho Animal como una rama del Derecho Ambiental, o si ambos son excluyentes; desde el análisis del Derecho Animal en sus orígenes en su desarrollo social y jurídico a partir de su evolución histórica. Esta disquisición es analizada a partir de la concientización de los seres humanos por el bienestar de los animales, incorporado en los ordenamientos jurídicos por decisión de los Estados, al decir de autores como Mosterín (1995), Bellido Jara (2007), Campos Serena (2011, pp. 1-22), Martin Blanco (2012, pp. 59-72).

El Derecho Animal ha emergido de manera paulatina en los países mediante la adopción de normas jurídicas en la materia y la creación de determinadas fundaciones internacionales. En 1979, la abogada estadounidense Tischler creó la fundación Animal Legal Defense Fund, reconocida como la primera organización dedicada a la promoción de la esfera del Derecho de los Animales y usando el Derecho para proteger las vidas y defender los intereses de los animales, en este mismo íter a mediados del siglo XIX en Inglaterra se constata que promulgaron las primeras Leyes de protección a los animales domésticos.

Este Derecho Animal, está concebido como el conjunto de derechos positivos y jurisprudenciales, en el cual el objeto del Derecho es la naturaleza legal, social y biológica de los animales. En los últimos años el estudio del Derecho Animal ha alcanzado un auge en su investigación y aplicación, debido al impulso realizado por las organizaciones ecologistas y protectoras de los animales, las que han exigido un tratamiento más considerado a los animales en virtud de la creencia de que estos poseen una estructura neuronal desarrollada y semejante a la que presenta el hombre, que con evidencia ya no pueden ser considerados desde el ámbito jurídico simplemente como cosas, pese a que en muchas legislaciones se les ve como tipos sui géneris de cosas, tal y como refieren autores como Regan (2006), Pocar (2009, pp.20-28) o Trujillo Cabrera (2009, pp. 69-82).

Ante la realidad innegable que los animales forman parte del entorno, de la sociedad, y que seguirán existiendo siempre, y que para que exista una buena convivencia con ellos, deben regularse normas jurídicas al respecto, que prohíban el maltrato en todas sus esferas y que lleve consigo medidas coercitivas ante conductas antijurídicas para lograr el respeto por los animales y una alimentación adecuada y sin violaciones en su proceso para los humanos.

En Cuba, sobre esta temática en la búsqueda epistemológica realizada, se constató que no existen investigaciones previas a partir del Derecho Ambiental, que aborden un tema tan sensible como la crueldad y el maltrato animal en la producción de alimentos publicadas en revistas científicas de Derecho, ni se reconoce en nuestro ordenamiento jurídico el Derecho Animal y la criminalización de conductas por el Derecho Penal de manera adecuada; no ocurre así desde las Ciencias Veterinarias, donde se constatan estudios señalando la necesidad de su regulación, para que se propicie el bienestar a los animales ante las conductas inadecuadas de los ciudadanos y de las personas jurídicas (Antúnez Sánchez, 2016). 


\section{DECÁLOGO PARA EL BIENESTAR ANIMAL EN LA PRODUCCIÓN DE ALIMENTOS}

Dentro de esta oleada interminable de violencia en el mundo, existe un tipo cuyas víctimas son las otras formas de vida, especialmente los animales no humanos, aunque esta forma de violencia ha sido ampliamente estudiada, parece pasar desapercibida ante nuestra sociedad, opacada por ese enorme monstruo que representa la violencia hacia nosotros mismos, y la necesidad de producir alimentos sin percibir o respetar los derechos de los animales, es por ello que ante la atención a estos aspectos, las Ciencias Veterinarias han delimitado el siguiente decálogo para el bienestar animal en la producción de alimentos por autores como Hammerstein (2007):

$\checkmark$ El bienestar animal, la calidad de los alimentos, y la salud humana van de la mano. Calidad ética y calidad de los alimentos han de ir juntas. Los animales son víctimas silenciosas de nuestros modos de vida, producción y consumo. El modelo intensivo de producción de las granjas industriales además de generar un sufrimiento animal que tiene las dimensiones de un holocausto también produce sufrimiento humano: la diversidad de productos locales y regionales, frescos, cercanos, autóctonos, y de alta calidad nutricional desaparecen de nuestros mercados a la vez que la masiva producción intensivo-química de alimentos genera numerosos efectos biocidas colaterales, y con ello graves problemas sanitarios y medioambientales. Una mejora en el bienestar y condiciones de vida de los animales durante la cría, el transporte y el sacrificio también repercutirá beneficiosamente sobre la calidad nutritiva final de la carne obtenida, los alimentos y la salud humana. Las prácticas del modelo mecanicista y artificializador presente en las granjas industrializadas de producción intensiva comporta un enorme e innecesario sufrimiento de animales vivos, y por ello han de sustituirse por otras formas productivas que, además de ofrecer condiciones de seguridad alimenticia, aporten mayores garantías de bienestar y salud tanto para los animales como para los consumidores humanos.

$\checkmark$ De los animales con vidas miserables a los animales con vidas felices. Se trata de pasar del sufrimiento animal generalizado mediante la producción intensiva de animales y de carne al bienestar animal en todos y cada uno de los eslabones del ciclo de la cadena productiva: desde el nacimiento y la crianza hasta el transporte y sacrificio. Son necesarias mejoras en el trato y las condiciones de vida de los animales criados para la alimentación humana de manera que se atiendan sus necesidades vitales permitiendo sus comportamientos naturales básicos para el buen desarrollo y bienestar de cada individuo. Deben desaparecer las experiencias organizadas de crueldad y de 
miedo que innecesariamente crean padecimientos constantes y enfermedad en los animales de las granjas industriales, como seres vivos sintientes que son. Deben eliminarse las prácticas violentas de encierro, aislamiento y amputación de sus cuerpos con castraciones y cortes de pico sin anestesia, marcado a fuego, manipulaciones genéticas para que produzcan más, hormonas para que crezcan rápidamente, aire saturado de amoníaco y convivencia con el propio excremento. En el caso de los pollos y gallinas de granja ha de establecerse un descanso de 6 horas en oscuridad absoluta por cada 24 horas, y los polluelos deben tener elementos que favorezcan la actividad de los animales, su salud y bienestar (por ejemplo, introduciendo balas de paja).

$\checkmark$ Del incumplimiento de la legalidad sobre el bienestar animal al control y normativas legislativas con poder sancionador. Urgen medidas de inspección y de aplicación de sanciones correctivas contra las prácticas de crueldad por el incumplimiento de las directivas europeas sobre el bienestar animal en el transporte y el sacrificio de los animales vivos. En el matadero los animales huelen y ven las matanzas de los individuos que les preceden, escuchan y perciben sus gritos y dolor. Todos los métodos de aturdimiento previo previstos por la legislación, si es que se usan, no aseguran el desvanecer a los animales, y en la gran mayoría de los casos están conscientes cuando se cortan sus yugulares, muchas veces colgados boca abajo de una pata.

$\checkmark$ Del sistema de jaulas de cría de animales de granja a su prohibición legal. Se trata de eliminar las privaciones, el miedo, el estrés y el confinamiento en masa en las vidas de los animales. El hacinamiento les impide moverse y expresar sus preferencias, y con ello tampoco pueden tener una espontánea y natural socialización con los individuos y grupos de su especie. También las llamadas jaulas enriquecidas deben ser prohibidas ya que no garantizan un espacio suficiente para moverse y no permiten a las gallinas muchos comportamientos naturales e instintivos.

$\checkmark$ Del maltrato animal de la producción intensiva a la información, la reflexividad y el aprendizaje sobre prácticas responsables con el bienestar animal. La educación ambiental sobre el bienestar animal ha de estar presente en las ofertas públicas especializadas de capacitación laboral agrícola y agroalimentaria con programas de formación e instrucción dirigidos a productores e impulsados por instituciones, sindicatos, agroindustria, y asociaciones de consumidores. Los productores ganaderos y granjeros han de poder acceder a los conocimientos y el uso prudente de recursos con los que poder detectar y corregir los problemas relacionados con el bienestar de los animales. Para un cambio social y cultural profundo y arraigado a favor de una ética y valores ampliados que incluyan la preocupación por el bienestar de otros seres vivos, es importante comenzar cuanto antes. El sistema de enseñanza ha de 
comprometerse en esta inmensa tarea urgente de innovación y socialización desde la más tierna infancia, desde los huertos y granjas escolares hasta los estudios, especialidades e investigación universitarias.

$\checkmark$ De las subvenciones europeas directas a la producción intensiva de animales a la eco-condicionalidad del bienestar animal. Las concesiones de las ayudas europeas deben supeditarse al estricto cumplimiento de la legislación europea sobre el bienestar animal. También en la importación europea de animales y alimentos de otros países debe garantizarse la eco-condicionalidad del bienestar Animal, y la Unión Europea (UE) ha de defender esta posición ante la Organización Mundial de Comercio (OMC). En los mercados globales deben eliminarse las subvenciones públicas a la exportación de animales vivos. Las ayudas públicas a la producción basada en el sufrimiento animal constituyen un dumping socioeconómico que lesiona la competitividad de los productores con bienestar animal, además de distorsionar y rebajar artificialmente los precios del mercado impulsando así el hundimiento las economías de países pobres.

$\checkmark$ Del transporte de animales vivos a largas distancias al transporte de vísceras, despojos y refrigerados. El transporte no ha de superar las 8 horas en total, o los $500 \mathrm{Kms}$ de recorrido, desde el punto de salida al de destino tanto para animales de matadero como para animales de engorde. El sacrificio ha de hacerse en mataderos cercanos a las explotaciones de crianza, especialmente si el destino es a terceros países que no están adheridos a los Convenios Internacionales para la protección de los animales. Se ha de acabar la imagen cotidiana de camiones abarrotados con animales vivos apelotonados y asustados que salen de las granjas industriales camino del sacrificio y hacen largos trayectos sin comida ni agua, hacinados, empujados y ajetreados por el viaje. La exportación de animales vivos para consumo debe ser sustituida por canales refrigerados.

$\checkmark$ Del gigantismo industrial de la producción a gran escala basado en el sufrimiento animal a las pequeñas y locales industrias alimentarias. $\mathrm{La}$ pequeña producción local y regional además de sufrir el acoso de la legislación europea en materia de exigencias de higiene también afronta la desventaja comparativa de los altos costes que lastran su competencia en mercados globales. Con el desarrollo de ayudas específicas a los productores con prácticas de bienestar animal se fomentarán la mejora de las condiciones de vida de los animales de granja, el desarrollo de la economía rural, y la mayor rentabilidad de los pequeños productores ganaderos y agricultores. Al premiar los esfuerzos dirigidos al bienestar animal este dejará de percibirse como un simple coste económico añadido al conjunto de la actividad productora y ganadera. Se trata de convertir las prácticas del bienestar animal en un valor 
añadido de calidad en los productos y en fuente de diversificación favoreciendo conjuntamente la economía de los productores locales y el bienestar de los animales y los consumidores humanos.

$\checkmark$ Del consumidor voraz y desinformado al nuevo consumidor que practica una ciudadanía reflexiva, responsable y ética. El consumo individual puede incorporar los valores éticos añadidos de bienestar animal en la elección de los productos, y con ello no reducir la compra a una comparación cuantitativa entre precios y calidades. Este nuevo consumidor pone en práctica nuevos valores sociales y medioambientales no reducibles a la rentabilidad económica, y con ello se expresan y fomentan unas nuevas formas sociales y culturales de ciudadanía responsable y solidaria a favor de la protección del bienestar animal.

$\checkmark$ De la desinformación sobre la composición, procesos e historia de los alimentos al sello de garantía de buenas prácticas de bienestar animal en el etiquetado. Mediante un claro y completo etiquetado deben ampliarse las opciones del consumidor individual. Garantizar los derechos a la información de los consumidores y contribuir con ello a una opinión pública informada y a un mayor sentido de responsabilidad por parte de los consumidores individuales. El etiquetado ha de incorporar una amplia información no manipulada y comprensible sobre los tratamientos tecnológicos y los ingredientes nutrientes naturales y sustancias químico-sintéticas añadidas en los productos alimenticios de la agroindustria. En el etiquetado se ha de incluir un sello o marca de garantía de bienestar animal, con ello se amplía el conocimiento y las opciones por parte de las consumidoras y consumidores en actos de compra que también expresan valores prácticos de conexión y protección con los seres vivientes que se producen para alimento humano. De igual manera, para realizar la función sanitaria e inspectiva o forense del veterinario el GEVHA en relación con la Asociación Americana de Medicina Veterinaria y la Asociación Canadiense de Medicina Veterinaria, establecen una serie de indicadores de maltrato animal, como siguen a continuación:

$\checkmark$ Indicadores de comportamiento: miedo extremo, agresión, sumisión, esconderse.

$\checkmark$ Indicadores por negligencia u omisión: desnutrición, pelo enredado, cascos o uñas largas, heridas crónicas, heridas infectadas por gusanos, enfermedades no tratadas, suciedad general.

Criterios que son de considerable valor para la regulación jurídica de los Derechos de los Animales en esta esfera. 


\section{TRACTO EVOLUTIVO DE LA PROTECCIÓN DE LOS ANIMALES. MARCO REGULATORIO}

En el corpus iuris civilis por Justiniano en Roma se encuentra la consideración de los intereses de los animales, al reflejar que: "El derecho natural es aquello que es dado a cada ser vivo y que no es propio al ser humano". Se puede constatar que en la Antigua Roma no se consideraba que eran personas, ni mucho menos que tenían derechos los esclavos, por lo tanto, iba a ser mucho más complicado que los animales pudieran tener alguna clase de respeto por parte de sus amos. La idea de "derechos de los animales" tenía aún menos relevancia en la vida cotidiana de la antigua Roma. Animales vivos eran preparados para la comida y se mató a miles de animales por diversión en los famosos juegos romanos.

En Grecia, se dividían las opiniones filosóficas clásicas hacia varios caminos. Una élite antropocéntrica sostenía la genealogía divina del hombre; otros afirmaban que hombres y animales compartían almas semejantes; los demás los asimilaban a cosas, como los romanos de donde el derecho tomó la concepción de res, rei con el sentido de cosas o bienes sobre los cuales el hombre impera con su dominio.

Aristóteles (1988) planteaba en su teoría biológica que, sólo el hombre tiene vida racional, idea seguida por la mayor parte de la doctrina tradicional del Derecho; sólo en el ser humano se dan conjuntamente la inteligencia y la voluntad, características que le otorgan libertad para accionar de acuerdo a su propia opción moral, lo que los transforma en sujetos con responsabilidad, esta es la razón por la que únicamente los seres humanos pueden ser titulares de derecho, excluyéndose de esta consideración a los animales. Se precia como desde la Antigüedad, los animales han sido catalogados como cosas para el Derecho, como simples objetos susceptibles de apropiación material y por ende de su libre disposición. Este hecho no es de extrañar, si analizamos que el propio hombre esclavizó durante siglos a los de su misma especie, por lo que entonces ¿Por qué tendría consideración alguna con seres vivos distintos a nosotros?

En el Derecho Romano, se concebía a los animales como cosas muebles o semovientes, condición que compartían con los esclavos, quienes eran considerados igualmente objetos. Los animales se clasificaban en tres grupos: animales fieros o salvajes (Ferae bestiae): eran aquellos que gozaban de libertad natural y podían ser apropiados por cualquier persona; los animales amansados o domésticos (Mansuetae o Mansuefactae): que, aunque gozaban de libertad, se encontraban bajo el control del hombre, mientras conservan la costumbre de volver a su dominio (animus revertendi); los Animales domésticos: eran los que se encontraban continuamente bajo la potestad del hombre.

Mahoma consideraba permisible matar a animales, aunque hacerlo sin necesidad aparente o con crueldad fue prohibido. Por el contrario, las sociedades hindúes y 
budistas desde el siglo 3 a.C. proclamaron un vegetarianismo amplio refiriéndose al principio de Ahimsa, el principio de no violencia. Por la equivalencia moral de animales y seres humanos unos reyes construyeron hospitales para animales enfermos. Matar a una vaca fue un delito tan serio como matar un hombre de alta casta, matar a un perro tan serio como matar a un intocable. El amor y la compasión son las creencias budistas más importantes, lo que explica por qué tantos budistas son vegetarianos.

El punto de vista del budismo hacia los animales es ilustrado mejor en las historias del Jataka (lecciones budistas), en las que se cuenta que Buda fue diferentes animales en encarnaciones previas. Las historias dicen que es igual matar animales que matar humanos, ya que como Buda todos hemos encarnado en la forma de animales. Al igual que Los Vedas, la ley budista del Karma también dice que aquellos que causen violencia y sufrimiento a seres vivos experimentarán el mismo dolor en algún momento en el futuro.

Otra fe con fuerte tradición de bondad y consideración hacia los animales es el Judaísmo. Algunos profetas judíos, tales como Amós y Miqueas, hablaron en contra de los sacrificios de animales, y muchos héroes judíos fueron elegidos por Dios debido a su amor a los animales. El Talmud, el libro sagrado de la ley cívica y ceremonial de los judíos, dice que antes de que el hombre se siente a la mesa debe alimentar primero a sus animales, porque no lo pueden hacer por sí mismos.

Mahoma declara que la sangre no es apta para el consumo humano y como consecuencia el proceso del sacrificio es complicado. Debe ser llevado a cabo por personas que observen la ley musulmana de orar cinco veces al día. Algunas sectas musulmanas tales como los Sufíes y Baháis han elegido el vegetarianismo porque lo ven como el máximo ideal espiritual. El profeta Mahoma, aunque fue vegetariano y enfatizó la compasión universal, condenando y evitando muestras de crueldad hacia los animales, no enseñó a la gente a evitar la carne por temor a desanimarlos a seguir la fe (Masri, Al-Hafiz Basheer, 1987).

El Cristianismo es otra fe que no es fuertemente vegetariana, aunque sus enseñanzas parecieran apoyar la idea. Los primeros cristianos seguían atentamente las escrituras que ordenaban una forma de vida estrictamente sin carne. Algunas teorías dicen que el mismo Jesús era vegetariano. Algunos movimientos religiosos que pertenecen a esta religión son los ortodoxos (pueblos: eslavos, griegos y balcánicos-orientales), protestantes (pueblos: germanos y anglosajones) y los católicos (Fernández Bulté, Carreras Cuevas \& Yáñez García, 1995).

El derecho al medio ambiente se reconoció como un requisito para disfrutar de una vida digna, donde el hombre pueda ejercer sus derechos a la libertad, la igualdad y al disfrute de condiciones de vida adecuadas. En consecuencia, en 1987, el Consejo de Administración del Programa de las Naciones Unidas y el Desarrollo (PNUMA), adoptó la decisión de presentar ante la Asamblea General el Informe 
de la Comisión Mundial sobre el Medio Ambiente, bajo el título de "Nuestro Futuro Común" conocido como "Informe Brundtland", y retomó la Carta Mundial del derecho de la diversidad biológica.

Con posterioridad, la Cumbre de la Tierra de 1992, genera varios instrumentos jurídicos internacionales; así, la Declaración de Río sobre Medio Ambiente y Desarrollo, donde se estableció un marco jurídico y un reglamento eficaz, para luego entrar en vigor la Convención sobre la Diversidad Biológica en 1993, y el Convenio de las Naciones Unidas sobre Cambio Climático en 1992, que han seguido evolucionando con el tiempo hasta la Cumbre del Clima celebrada en París en el 2015 (Rey Santos 2005-2008, Caraballo Maqueira, 2014, Antúnez Sánchez, 2016).

El hecho de que el Derecho Ambiental presente autonomía científica y didáctica y una rica normatividad, es la expresión indubitable de su existencia como ciencia y rama jurídica. Se le considera como una nueva rama jurídica que regula la conducta humana estableciendo principios, exigencias, normas y prescripciones jurídicas, otorgando a los sujetos los derechos, las atribuciones, y prohibiciones: es el instrumento, la herramienta legal que regula y autorregula el comportamiento humano ante la conservación de la diversidad biológica, como se señalara en los estudios realizados desde 1998 hasta 2016 por juristas como González Novo (1998), Fernández Rubio-Legrá (1999), Ayes Ametller (2003), Di Cagno (2005), Hernández Torres (2007), Toledano Cordero (2012), Cánovas González (2012), Soler Del Sol (2013), Rey Santos (2013), Caraballo Maqueira (2014) o Antúnez Sánchez (2016) desde la perspectiva del Derecho Ambiental en la nación cubana, en especial sobre el tema del bienestar de los animales.

Se justiprecia como el aporte del concepto de desarrollo sostenible, a partir de que este constituye un mega principio para el Derecho Ambiental moderno a tener en cuenta por la Administración Pública ante los nuevos paradigmas; uno de sus mayores pasos de avance, al ampliar su ámbito, motiva en su ejecución al Estado vigilante las variables sociales y económicas, asunto que el Derecho no estaba acostumbrado a lidiar, aunque aún no se tenga una respuesta adecuada en cuanto a la protección del medio ambiente como un bien público de uso colectivo desde su reconocimiento en los textos constitucionales y en el desarrollo normativo de cada nación, como lo han ido ponderando autores como Brañes Ballesteros (1995), Martín Mateo (1998), Bellorio Clabot (2004), Martín-Retortillo Báquer (2006), Hernández Torres (2007), Rey Santos (2008), Quirola Suárez (2009), Afonso Da Silva (2009), De Medeiros García (2010, 133-204), Fix-Zamudio (2010), Zaffaroni (2011), Villavella Armengol (2011), Foy Valencia (2012), Toledano Cordero (2012), Caferrata (2013), Franciskovic Ingunza (2013) o Bellorio Clabot (2013) desde el siglo XX hasta la actualidad, entre los aportes de mayor relevancia desde el Derecho constitucional en Hispanoamérica. 
Son reconocidos tres grandes problemas ambientales globales y su incidencia en la biodiversidad, como el agotamiento de la capa de ozono, el calentamiento global y la pérdida de diversidad biológica. La pérdida de diversidad biológica ha constituido un fenómeno a lo largo de todos los tiempos desde el nacimiento de las formas de vida en la Tierra; sin embargo, han sido productos de sucesos naturales en su mayoría, como cambios extremos climáticos en el planeta, con las erupciones volcánicas, la caída de meteoritos, entre otros. Con todo, el calentamiento global ha provocado que las cifras de especies animales amenazadas en peligro de extinción sean cerca de 5500 cada año, de ahí la necesidad de su protección adecuada, como lo han ponderado Brañes Ballesteros, Bustamante Alsina (1995), Martín Mateo (1998), Betancor Rodríguez (2001), Pigretti, Prieur (2003), Bellorio Clabot (2004), De Besa Antunes, Soriano García, Brufao Curiel (2010), Di Trindade Amado, Beltrao, Silveira Da Rocha Sampaio (2011), Parejo Alfonso (2013) y Lozano Cutanda (2015), en sus estudios sobre el desarrollo y evolución del Derecho Ambiental en el contexto internacional y en el de cada país.

Se conoce como derechos de los animales, a las ideas postuladas por corrientes de pensamiento y a la subcorriente del movimiento de liberación animal que sostienen que la naturaleza animal es un sujeto de Derecho, cuya novedad reside en que esta categoría sólo ha pertenecido a personas naturales y jurídicas, es decir el ser humano. Los humanos siempre han tratado de darle a los animales una consideración especial, ejemplo de ello es la domesticación, en algunas culturas son considerados sagrados pasando por el trato ético o el bienestar animal, hasta considerar que los animales merecen derechos tradicionalmente reconocidos sólo en los humanos y hay otras, en las que se pasa al otro extremo donde utilizan a los animales según les plazca o puedan servirles.

No se debe confundir el derecho de animales como parte de la doctrina jurídica, toda vez que el marco jurídico de algunos países donde el objeto de Derecho es la libertad de conducta de los animales en su ambiente natural y el trato que reciben en un hábitat humano. Es aceptable la idea de que los animales puedan ser explotados por los humanos para comida, vestido, u otras razones, esta proviene básicamente de tres fuentes principales: la costumbre de muchos pueblos de las primeras etapas de la vida humana en la Tierra de conseguir comida de la caza y la pesca y, posteriormente, de la ganadería; el concepto teológico de dominio basado en el Génesis (1:20-28) donde es dado a Adán el dominio sobre el mundo no humano; la suposición de que los animales no pueden poseer derechos porque no tienen capacidades tales como razonamiento, lenguaje o conciencia. Dicha suposición es contestada por los defensores de los animales mediante el argumento de casos marginales.

Se valora que el Derecho Animal, constituye la rama del Derecho que regula la protección de los animales no humanos. Los derechos de los animales como tema 
controvertido, es debido a que no existe consenso sobre los mismos, ni acuerdos internacionales al respecto que lo regulen como ha sido con el Derecho Ambiental. Independientemente de las posturas heredadas de las Conferencias Internacionales sobre el Medio Ambiente, que dieron inicio al surgimiento del Derecho Ambiental en la Conferencia de Estocolmo sobre el Medio Humano en 1972, en la que se regula y nace la cultura antropocentrista, la que defiende: "De todas las cosas en el mundo, los seres humanos son lo más valioso. Ellos son quienes promueven el progreso social, crean riqueza social, desarrollan la ciencia y la tecnología y, con su duro trabajo transforman el Medio Ambiente"; o la cultura biocentrista expuesta en la Declaración de Nairobi de 1982, donde se establece que: "Toda forma de vida es única y merece ser respetada, cualquiera que sea su utilidad para el hombre, y con el fin de reconocer a los demás seres vivos su valor intrínseco, el hombre ha de guiarse por un código de acción moral". Cualquiera de las dos posturas anteriores planteadas defiende en cierto modo la protección de los animales no humanos, lo que varía es el alcance jurídico de dicha protección (Rey Santos, 2012, p.51).

Aunque estos conceptos son propios del Derecho Ambiental y no directamente del Derecho Animal, se extienden al ámbito de regulación de dicha materia, en lo personal los autores se afilian a la supremacía de la cultura biocentrista sobre la cultura antropocentrista, por lo que se considera que será necesario la protección de los animales independientemente de los beneficios que estos aporten al ser humano.

Estas lecturas, permiten plantear el interrogante en este ensayo jurídico: ¡tienen derecho los animales?; en su libro Liberación Animal Singer (1999), afirmó que el principio básico de igualdad no requiere de un trato igual o idéntico, solo requiere de una consideración igual. Ésta es una diferencia importante cuando se habla de los derechos de los animales. A menudo, la gente se pregunta si los animales deben tener derechos, la respuesta es sencilla: sí, definitivamente los animales merecen vivir su vida sin sufrimiento y sin explotación. Los animales han sido y siguen siendo considerados, en la mayoría de los países del mundo, como bienes o cosas corporales, bajo la denominación de semovientes, o sea, cosas que tienen la aptitud de moverse o trasladarse de un lugar a otro por sí mismos.

Se considera que los animales tienen derecho a una vida sin sufrimiento, que para efectos de entenderla, en este ensayo jurídico se ha asimilado la vida digna de la cual gozan los seres de la especie humana, que aunque debería existir igualdad, esta no se presenta, ya que no todos los seres humanos cuentan con las mismas situaciones de vida, por lo tanto no todos pueden acceder a lo mismo, para ciertas personas algo se puede considerar vital o digno y para otras no; todo varía según la clase social, en el entorno en que se encuentren, la situación económica y las creencias o gustos que cada quien tenga (Mosterín, 1995, Wolf, 2001, De Lora, 2003, Pérez Monguió, 2005, León-Guzmán, 2006, Estrada Celsi, 2008, Avellaneda 
Vásquez, Peñuela Navarrete, 2010, Brels, 2012, Capo Martí, 2012, Martín Blanco, 2012, Rabal Méndez, 2014).

Lo descrito, debería aplicarse a los animales, estos deben ser considerados cada uno como tal, como un animal no humano, que siente, sufre, tiene necesidades que deben ser atendidas, tener en cuenta su vida, el servicio para el que fue creado y de ese modo tener un trato respetuoso hacia ellos y combatir cualquier circunstancia que genere sufrimiento, ya que por el simple hecho de que estos individuos no hablen ni razonen, no podemos caer en el error que tampoco sufren.

En el mundo, se constata como fueron creadas las primeras sociedades de "protección animal", durante la revolución industrial y las primeras víctimas defendidas fueron las que efectuaban la llamada "tracción a sangre", es decir, caballos, asnos y mulas, cuyo maltrato era habitual y a la vista de todos. Elementos que permitirán realizar un análisis de las normas jurídicas que están vinculadas con la protección, el maltrato y la crueldad animal desde las Ciencias Jurídicas y en especial desde la normativa penal.

\section{NORMATIVAS JURÍDICAS EN RELACIÓN CON LA PROTECCIÓN, MALTRATO Y CRUELDAD DIRIGIDA A LOS ANIMALES}

La primera Ley conocida en defensa de los animales fue de origen irlandés. Ello ocurrió en 1635 y se prohibió fisurar la lana del ganado ovino y atar arados a las colas de los caballos debido al sufrimiento del animal. En el año 1641, la colonia estadounidense de Massachusetts Bay aprobó un sistema de leyes protegiendo a animales domesticados. Estas leyes fueron basadas en el Massachusetts Body of Liberties (Cuerpo de Libertades de Massachusetts). Ello dio lugar a que se constituyera a nivel global en 1824, la fundación en Londres de la Royal Society for Prevention of Cruelty to Animals, -Sociedad Real para la Prevención de la Crueldad Animal-, como la primera sociedad protectora de animales en el mundo, fundada inicialmente para proteger a los animales de granja, que más tarde ampliaría sus esfuerzos para incluir a todos los animales, y en 1840, se le concedió una carta de la Reina Victoria, convirtiéndose en la Sociedad Real para la Prevención de la Crueldad contra los animales.

De esta Sociedad Protectora de Animales en Inglaterra existen sucursales, fundadas por los grupos locales de defensores del bienestar de los animales, que ofrecen los servicios veterinarios tanto a los animales domésticos y silvestres, junto con programas educativos, Los inspectores de RSPCA patrullan muchas partes de Inglaterra para hacer cumplir las leyes establecidas para proteger a los animales de tratos crueles. Además de trabajar en el campo, la Sociedad Protectora de Animales coopera con las organizaciones policiales y grupos de defensa de otros animales. 
Otra organización es la American Society for Prevention for Cruelty to Animals -Sociedad Americana para la prevención de la crueldad animal en los Estados Unidos de América-. Haciendo una comparación entre la RSPCA y la ASPCA encontramos que esta última tiene una ventaja comparativa sobre la británica debido a su presencia en un gran número de estados del país; la ciudad de Nueva York, tiene un departamento de ejecución de la legislación animal (Humane Law Enforcement Department), sus poderes son equivalentes a los de la policía, permitiéndole requisar predios y realizar arrestos, mientras que la RSPCA si quisiera hacer alguno de aquellos actos debe ser asistida por la policía.

A pesar de eso la RSPCA es, en términos de cantidad de acciones, muy superior a la ASPCA. También en esta nación existe la People for Ethical Treatment to Animals -Personas para el Tratamiento Ético con los Animales-, otra organización para la defensa y protección de los derechos de los animales fundada en 1980. Se constata como la década de los 70, y principios de los 80 del pasado siglo XX, tiene lugar el denominado "Movimiento de los Derechos Animales", siendo su máximo exponente Singer, quién con su libro Liberación Animal, se transformó en el padre del liberacionismo. A pesar del impacto de la publicación, su filosofía no se encuadra dentro de la teoría de los derechos, dado que se enmarca en una corriente ética utilitarista, a la que clásicamente se oponen las éticas deontológicas o del deber.

Se aprecia también, cómo en el siglo XX, se aprobó la Declaración Universal de los Derechos del Animal en 1978 en la UNESCO y por la ONU. Es así que, actualmente, ha permitido que los derechos de animales reconocidos en cuerpos jurídicos internacionales, ya se enseñen en diversas Facultades de Derecho, como es el caso de los Estados Unidos de América, en universidades como la de Harvard, Stanford y UCLA, entre otras.

En la Unión Europea, se constata como desde la Universidad Autónoma de Barcelona en España, se imparte el Máster de Europa en Derecho Animal y Sociedad (Animal Law and Society) a partir del 2011, por la relevancia e importancia del tema para preservar la naturaleza como un bien público de uso colectivo. De igual modo, en la Facultad de Derecho de esta Universidad se oferta el curso en Derecho de los animales. Se valora que cada vez hay más asociaciones de las abogacías estatales y locales para defender los derechos de los animales. Aunque existe poco precedente legal pro-animal, por lo que cada caso presenta una oportunidad para cambiar el futuro legal de los animales, tal y como lo señalan autores como Dorado y Horta sobre el cambio de paradigma en ética animal a partir de 2009-2014.

La legislación penal dentro de los ordenamientos jurídicos en la Unión Europea también ha recogido este cambio, como se constata en el Código Penal Francés, que incluye una serie de normas tanto represivas como también bienestaristas, contemplándose en forma separada, en los artículos 654-1 y 521-1, respectivamente, el maltrato y los actos crueles, constituyendo sólo este último delito, siendo 
el maltrato una simple falta. No hay una definición legal de estos conceptos, por lo que la inclusión de la conducta en uno u otro tipo penal dependerá de la tarea discrecional del juez. Para la jurisprudencia francesa un acto cruel "se distingue de la simple brutalidad, en que está inspirado por maldad y manifiesta intención de infligir sufrimiento"; desde esta perspectiva, es la intencionalidad la que determina la crueldad del acto.

La sanción de una y otra conducta va desde una multa de hasta los 750 euros, pudiendo además ser privado el condenado de la posesión del animal, en el caso de maltrato, pena que, tratándose del delito de crueldad, consiste en dos años de prisión, además de una multa ascendente a los 30.000 euros, contemplando como pena accesoria la posibilidad de prohibir la posesión de un animal, sea con carácter temporal o definitivo. Esta misma disposición castiga también, y con la misma pena señalada anteriormente, el abandono de un animal.

Otro de los cuerpos jurídicos que contiene normas relativas a los animales en el Derecho francés es el Código Rural, que en su artículo 214-1, reconoce expresamente que "todo animal es un ser sensible", por lo cual su propietario debe procurarle condiciones compatibles con los imperativos biológicos de su especie, reconociendo en el artículo siguiente, que todo hombre tiene derecho a tener animales, teniendo además el deber de no maltratarlos, ya se trate de animales domésticos, salvajes domesticados o tenidos en cautiverio, extendiéndose la responsabilidad, de acuerdo a lo señalado en el artículo 121-2, del Código Penal, en caso de maltrato, tanto a personas naturales como jurídicas.

En cuanto a la experimentación con animales, además del delito contemplado en el artículo 512-2, del Código Penal, que sanciona el hecho de realizar experimentos o investigaciones científicas o experimentales sobre animales sin ajustarse a las prescripciones establecidas por ley, el artículo 214-3 del Código Rural señala que esta experimentación, sea médica o científica, debe limitarse a los casos de estricta necesidad. Se impone a los investigadores el deber de buscar una solución conciliadora con el respeto hacia el animal, procurando que su salud y bienestar no se amenacen inútilmente. Así el Estatuto para una ética de experimentación con animales dispone en su artículo 2, que "los animales son seres sensibles y provistos de capacidades cognitivas y emocionales. Son capaces de sufrir".

En España, el Derecho sigue al francés en lo que se refiere a la naturaleza de los animales, rigiéndose los animales domésticos por las reglas generales aplicables a los bienes muebles. El Código Penal español, contempla en el Capítulo IV, Titulo XVI, del Libro II, titulado "De los delitos relativos a la protección de la flora, fauna y animales domésticos", el delito de maltrato animal en el artículo 337, que establece que "los que maltrataren con ensañamiento e injustificadamente a animales domésticos causándoles la muerte o provocándoles lesiones que produzcan un grave menoscabo físico, serán castigados con la pena de prisión de tres meses a un año 
e inhabilitación especial de uno a tres años para el ejercicio de profesión, oficio o comercio que tenga relación con los animales" (Esteve Pardo, 2008).

El Código Penal también incluye normas relativas a la protección animal en el Título III, del Libro III, denominado "Faltas contra los intereses generales"; así, el artículo 632.2 sanciona a "los que maltrataren cruelmente a los animales domésticos o a cualquiera otros en espectáculos no autorizados legalmente, sin incurrir en los supuestos del artículo 337, serán castigados con la pena de multa de veinte a sesenta días o trabajos en beneficio de la comunidad de veinte a treinta días". Esta disposición resulta deficiente, esto porque en primer lugar hace referencia a un "maltrato cruel", por lo tanto, si el "maltrato no es cruel", no se configura la falta, la cual no toma en consideración el sufrimiento animal, toda vez que no se necesita crueldad para causar sufrimiento, debiendo bastar el maltrato. Además se requiere que este maltrato cruel sea ejercido en espectáculos públicos no autorizados legalmente, por lo que también se excluye de la aplicación de la norma los maltratos, por muy crueles que estos sean, cuando estén autorizados, lo que equivale a admitir la legitimidad general del maltrato animal, con la excepción señalada, tal y como lo refieren en sus estudios autores como Tafalla (2006, pp. 1-6), Castro Álvarez (2007, pp. 1-10), Brels (2012, pp. 1-6), Capo Martí (2012, pp. 1-6) y Arana García (2013).

Así lo ha interpretado también la jurisprudencia, a modo de ejemplo, encontramos la sentencia de la Audiencia Provincial de Segovia, de 15 de septiembre de 1998, que absolvió a un sujeto que maltrató a un caballo hasta ocasionarle la muerte, puesto que este no puede considerarse, de acuerdo al fallo, animal doméstico, ni tampoco tal acción fue realizada en un espectáculo público como exige el artículo 632, del Código Penal. Respecto a las corridas de toros, por encontrarse generalmente permitidas, quedan excluidas del tipo penal. La doctrina jurídica estima que este tema podría llegar a constituir ilícito en el Derecho español mediante la regulación que den las Comunidades Autónomas, algunas de las cuales ya han prohibido mediante leyes de protección animal actividades tales como la lucha de perros, peleas de gallos, tiro al pichón y otras costumbres similares.

En el desarrollo sustantivo, se constata cierto desarrollo legislativo en las leyes 5/1995, Sobre protección de animales utilizados para experimentación y otras finalidades, 8/2003, de Sanidad Animal, 11/2003, de Protección de los Animales, 29/2006, del Medicamento, y 32/2007, para el cuidado de los animales en su explotación, transporte, experimentación y sacrificio.

Alemania fue el primer Estado de la Unión Europea en otorgar rango constitucional a la protección de los animales. A partir del año 2002, el parlamento alemán aprobó la reforma a la Constitución Fundacional de la República del año 1949, enmienda que consiste en añadir las palabras "y los animales", al artículo 20 de dicho texto, el que obliga al Estado a proteger la vida humana. Este artículo señala 
actualmente que "El Estado toma la responsabilidad de proteger los fundamentos naturales de la vida y de los animales en interés de las futuras generaciones".

En cuanto al sentido de esta disposición, la Ministra de Consumo y Agricultura de la época, Kuenast, informó al periódico The Guardian, que "la reforma constitucional no daba a los animales los mismos derechos que a los seres humanos", teniendo siempre la prioridad la persona humana, diciendo que estas modificaciones "podrían conducir a una nueva legislación que limite los experimentos con animales en casos como los laboratorios de cosméticos o analgésicos” (Klöepfer, 2012).

En Austria, además de reconocer la naturaleza diferenciada de los animales y los objetos, se sanciona como delito en el artículo 222 del Código Penal, que data de 1974, el maltrato animal, para el cual se contemplan penas privativas de libertad de hasta un año o multa de hasta 360 tarifas diarias.

Suiza, a diferencia de otros ordenamientos jurídicos, extendió la protección a todas las criaturas vivientes, incluyendo a las plantas, con base en la declaración de la dignidad de las mismas. La Ley federal de protección animal del año 1978, prescribió reglas de conducta que deben ser observadas en el trato con los animales [...] para asegurar su protección y bienestar" (artículo 1.1). En el año 2000 fue incorporado el artículo 80 de la Constitución -con el título "Protección de los Animales"-, que prevé el dictado de normas sobre "protección de los animales, su mantenimiento y cuidado, su utilización, los experimentos y los atentados a la integridad de animales vivos, el comercio y el transporte de animales y su matanza". "No se trata, de una declaración que incida en la obligación moral del ser humano de respetar la naturaleza, sino que, desde hace más de treinta años, constituye una obligación de carácter constitucional acogida y refrendada por la legislación tanto federal como cantonal, para optimizar la aplicación y la inserción en la normativa de las restricciones y condiciones de protección de los animales. El concepto de dignidad de las criaturas tiene su anclaje en las ideas del filósofo Lauritz Smith (1791) y del teólogo Karl Barth (1945) quien formuló la idea de que los animales tienen una dignidad propia, merecedora de protección”.

En América Latina se aprecia en México la Ley protectora de animales del Estado de México, de 1985. Comienza este texto en el Capítulo I, efectuando una declaración de objetivos, siendo estos la protección de los animales, tanto domésticos como silvestres que no sean nocivos para el hombre así como también, el evitar cualquier acción de crueldad o maltrato innecesarios, señalando el artículo 2, que sus disposiciones son de interés público, estableciendo también el artículo 3, que el objeto de la ley se orientará, entre otras cosas, a "fomentar el amor, respeto y consideración” para con los animales. Bobbio (1995), De Medeiros García (2010, pp. 133-204).

En Chile, la legislación en el Código Penal sanciona como delito el maltrato animal en el artículo 291, regulando que: "El que cometiera actos de maltrato o 
crueldad con los animales, será castigado con la pena de presidio menor en su grado mínimo y multa de uno a diez ingresos mínimos mensuales o solo esta última”. En la práctica chilena esta sanción no ha impedido que dichos actos de crueldad y maltrato animal cesen. Dicha conducta, tipifica y sancionada en el Código Penal, deja un amplio margen de interpretación por parte del juez, ya que se regula tanto el maltrato como la crueldad. La legislación chilena se centra en el bienestar animal para la seguridad de los humanos, no por el valor de los animales en sí mismos, considerando al animal como simples objetos incapaces de experimentar sensaciones como el sufrimiento y el dolor. La Ley n. 19.300, aborda el medio ambiente desde una perspectiva de gestión integral a través de principios básicos, utilizando aquellos instrumentos de política ambiental que apoyen y faciliten dicha gestión para su consolidación práctica con la participación activa de todos los ciudadanos. La protección animal comienza por su calificación jurídica. El Derecho nacional equipara jurídicamente los animales a las cosas, para asegurar su aprovechamiento, es el caso de la Ley n. 19.473, de Caza, la Ley n. 20.293, que Protege a los Cetáceos e introduce modificaciones a la Ley n. 18.892, General de Pesca y Acuicultura. Las reglas generales para la experimentación con animales se consagran en la Ley n. 20.380, sobre protección animal. Conforme a esta disposición: "sólo podrán practicarse por personal calificado, que evitará al máximo su padecimiento”. En el Derecho nacional, no existe una prohibición al uso de animales en circos. La Ley n. 20.380 sólo contempló la siguiente disposición protectriz: "Los circos, parques zoológicos y otros lugares destinados al espectáculo o exhibición de los animales (...) deberán contar con las instalaciones adecuadas a las respectivas especies y categorías de animales para evitar el maltrato y el deterioro de su salud". La Ley n. 20.417 señala el mandato de clasificación en los siguientes términos: "El reglamento fijará el procedimiento para clasificar las especies de plantas, algas, hongos y animales silvestres, sobre la base de antecedentes científico-técnicos, y según su estado de conservación, en las categorías recomendadas para tales efectos por la Unión Mundial para la Conservación de la Naturaleza (UICN) u otro organismo internacional que dicte pautas en estas materias" (Franciskovic Ingunza, 2013).

En Argentina encontramos la Ley n. 14.346, de protección animal, la que, a pesar de no presentar mayor novedad en la materia, contempla, a diferencia de la ley chilena una interpretación auténtica de lo que debe entenderse por malos tratos, estableciendo en el artículo 2, de dicho texto un catálogo de conductas constitutivas de este delito, proporcionando así mayor seguridad jurídica en su aplicación, al decir de Alterini (2009, pp. 60-68), Bellorio Clabot (2013), Lorenzetti (2013) y Caferrata (2013). La Constitución Política de Argentina de 1994, en la primera parte, capitulo segundo, denominado "Nuevos Derechos y Garantías", artículo 41, establece que "Todos los habitantes gozan del derecho a un ambiente sano, equilibrado, apto para el desarrollo humano y para que las actividades productivas 
satisfagan las necesidades presentes sin comprometer las de las generaciones futuras, y tienen el deber de preservarlo”. El daño ambiental generará prioritariamente la obligación de recomponer, según lo establezca la ley. Las autoridades proveerán a la protección de este derecho, a la utilización racional de los recursos naturales, a la preservación del patrimonio natural y cultural y de la diversidad biológica, y a la información y educación ambientales. Esta Carta Fundamental tampoco hace referencia alguna al tema animal (Serra, 2013, pp. 1-9).

En Ecuador, la Constitución de 2008, reconoce derechos para la naturaleza en general, concepto que incluye también los animales. Conforme a su artículo 71, "La naturaleza o Pachamama, donde se reproduce y realiza la vida, tiene derecho a que se respete integralmente su existencia y el mantenimiento y regeneración de sus ciclos vitales, estructura, funciones y procesos evolutivos. Toda persona, comunidad, pueblo o nacionalidad podrá exigir a la autoridad pública el cumplimiento de los derechos de la naturaleza. Para aplicar e interpretar estos derechos se observarán los principios establecidos en la Constitución, en lo que proceda. El Estado incentivará a las personas naturales y jurídicas, y a los colectivos, para que protejan la naturaleza, y promoverá el respeto a todos los elementos que forman un ecosistema”. Dentro del Capítulo Segundo "derecho al buen vivir", sección segunda denominada como "Ambiente sano", artículo 14, "se reconoce el derecho de la población a vivir en un ambiente sano y ecológicamente equilibrado, que garantice la sostenibilidad y el buen vivir, sumak kawsay. Se declara de interés público la preservación del ambiente, la conservación de los ecosistemas, la biodiversidad y la integridad del patrimonio genético del país, la prevención del daño ambiental y la recuperación de los espacios naturales degradados”. En el artículo 15, textualmente se dispone que: "El Estado promoverá, en el sector público y privado, el uso de tecnologías ambientalmente limpias y de energías alternativas no contaminantes y de bajo impacto. La soberanía energética no se alcanzará en detrimento de la soberanía alimentaria, ni afectará el derecho al agua. Se prohíbe el desarrollo, producción, tenencia, comercialización, importación, transporte, almacenamiento y uso de armas químicas, biológicas y nucleares, de contaminantes orgánicos persistentes altamente tóxicos, agroquímicos internacionalmente prohibidos, y las tecnologías y agentes biológicos experimentales nocivos y organismos genéticamente modificados perjudiciales para la salud humana o que atenten contra la soberanía alimentaria o los ecosistemas, así como la introducción de residuos nucleares y desechos tóxicos al territorio nacional". Asimismo, el texto constitucional de Ecuador señala en su artículo 72, que "la naturaleza tiene derecho a la restauración. Esta restauración será independiente de la obligación que tienen el Estado y las personas naturales o jurídicas de indemnizar a los individuos y colectivos que dependan de los sistemas naturales afectados”. En los casos de impacto ambiental grave o permanente, incluidos los ocasionados por la explotación de 
los recursos naturales no renovables, el Estado establecerá los mecanismos más eficaces para alcanzar la restauración, y adoptará las medidas adecuadas para eliminar o mitigar las consecuencias ambientales nocivas. El artículo 73 establece que "el Estado aplicará medidas de precaución y restricción para las actividades que puedan conducir a la extinción de especies, la destrucción de ecosistemas o la alteración permanente de los ciclos naturales. Se prohíbe la introducción de organismos y material orgánico e inorgánico que puedan alterar de manera definitiva el patrimonio genético nacional." Y el artículo 74 indica que "las personas, comunidades, pueblos y nacionalidades tendrán derecho a beneficiarse del ambiente y de las riquezas naturales que les permitan el buen vivir. Los servicios ambientales no serán susceptibles de apropiación; su producción, prestación, uso y aprovechamiento serán regulados por el Estado".

Su desarrollo en el derecho sustantivo se aprecia en la Ley forestal y de conservación de áreas naturales y vida silvestre, Ley n. 74. RO/64 de 1981, que establece que el cumplimiento de este cuerpo jurídico le corresponderá a la Guardia Forestal del Ministerio de la Agricultura y Ganadería, y a la Policía Nacional. Las infracciones de esta norma se sancionan con multas en la vía administrativa y les es aplicable el artículo 65, del Código Penal. También en el ordenamiento jurídico de Ecuador, existe la Ley de Fomento y Desarrollo Agropecuario, y quienes la incumplan son responsables de la indemnización de daños y perjuicios. Estas acciones son competencia de los Jefes de las unidades del patrimonio de áreas naturales del Estado, de los Jefes de Distritos Forestales y del Director Nacional Forestal (Quirola Suárez \& Melo, 2009, Wolkmer, 2010).

En Bolivia, la Constitución, en la parte de la "Estructura y Organización Funcional del Estado”, Título III "Órgano Judicial y Tribunal Constitucional Plurinacional”, Capítulo Tercero "Jurisdicción Agroambiental" se establece en el artículo 186 que "el Tribunal Agroambiental es el máximo tribunal especializado de la jurisdicción agroambiental. Se rige en particular por los principios de función social, integralidad, inmediatez, sustentabilidad e interculturalidad." El artículo 189, establece cuales son, entre otras, las atribuciones de dicho Tribunal, además de las señaladas por la ley: "1. Resolver los recursos de casación y nulidad en las acciones reales agrarias, forestales, ambientales, de aguas, derechos de uso y aprovechamiento de los recursos naturales renovables, hídricos, forestales y de la biodiversidad; demandas sobre actos que atenten contra la fauna, la flora, el agua y el medio ambiente; y demandas sobre prácticas que pongan en peligro el sistema ecológico y la conservación de especies o animales. 2. Conocer y resolver en única instancia las demandas de nulidad y anulabilidad de títulos ejecutoriales. 3. Conocer y resolver en única instancia los procesos contencioso-administrativos que resulten de los contratos, negociaciones, autorizaciones, otorgación, distribución y redistribución de derechos 
de aprovechamiento de los recursos naturales renovables, y de los demás actos y resoluciones administrativas. 4. Organizar los juzgados agroambientales".

En la Tercera Parte de la Constitución, denominado "Estructura y Organización Territorial del Estado" Título I, "Organización Territorial del Estado" Capitulo octavo "Distribución de Competencias" el artículo 298, establece: "I. Son competencias privativas del nivel central del Estado: inciso 20. Política general de Biodiversidad y Medio Ambiente". El Artículo 299 indica que "II. Las siguientes competencias se ejercerán de forma concurrente por el nivel central del Estado y las entidades territoriales autónomas: 1. Preservar, conservar y contribuir a la protección del medio ambiente y fauna silvestre manteniendo el equilibrio ecológico y el control de la contaminación ambiental." En el artículo 302 se determina quiénes son las autoridades competentes encargadas de dichas atribuciones: "I. Son competencias exclusivas de los gobiernos municipales autónomos, en su jurisdicción, entre otras atribuciones, la establecida en el inciso 5, "Preservar, conservar y contribuir a la protección del medio ambiente y recursos naturales, fauna silvestre y animales domésticos"'. Mientras que el artículo 304, establece que "las autonomías indígenas originario campesinas podrán ejercer las siguientes competencias compartidas: inciso 4. "Control y regulación a las instituciones y organizaciones externas que desarrollen actividades en su jurisdicción, inherentes al desarrollo de su institucionalidad, cultura, medio ambiente y patrimonio natural."

El Capitulo denominado "Amazonia”, en el Artículo 391, señala, "I. El Estado priorizará el desarrollo integral sustentable de la amazonia boliviana, a través de una administración integral, participativa, compartida y equitativa de la selva amazónica. La administración estará orientada a la generación de empleo y a mejorar los ingresos para sus habitantes, en el marco de la protección y sustentabilidad del medio ambiente". Por otro lado, literalmente se señala que las especies nativas de origen animal y vegetal son Patrimonio Natural de Bolivia y que el Estado establecerá las medidas necesarias para su conservación, aprovechamiento y desarrollo. También se regula sobre el Tribunal agroambiental señalando que es el máximo tribunal especializado en materia agroambiental así como el encargado de resolver recursos de casación y nulidad en las acciones reales; agrarias; forestales; ambientales; de aguas; derechos de uso y aprovechamiento de los recursos naturales renovables, hídricos, forestales y de la biodiversidad; demandas sobre actos que atenten contra la fauna, la flora, el agua y el medio ambiente; y demandas sobre prácticas que pongan en peligro el sistema ecológico y la conservación de especies o animales (Wolmer, 2010).

Colombia, por su parte, en La Constitución Política Colombiana de 1991, en el título I "De los principios fundamentales" capítulo 3 denominado "De los derechos colectivos y del ambiente" establece en el artículo 79, "Que todas las personas tienen derecho a gozar de un ambiente sano. La ley garantizará la participación 
de la comunidad en las decisiones que puedan afectarlo. Es deber del Estado proteger la diversidad e integridad del ambiente, conservar las áreas de especial importancia ecológica y fomentar la educación para el logro de estos fines". El artículo 80, establece que "El Estado planificará el manejo y aprovechamiento de los recursos naturales, para garantizar su desarrollo sostenible, su conservación, restauración o sustitución. Además, deberá prevenir y controlar los factores de deterioro ambiental, imponer las sanciones legales y exigir la reparación de los daños causados. Asimismo, cooperará con otras naciones en la protección de los ecosistemas situados en las zonas fronterizas". En cuanto a los animales no regula específicamente nada (Wolmer, 2010).

Se aprecia en la sistematización de los principales elementos regulados en los textos constitucionales que, en este avance en la protección de los animales para su bienestar, ha estado influido directamente por el modelo en el cual cada legislación se inspira. Así, se observan diferencias en la materia según se trate de ordenamientos basados en la tradición romana, o por el sistema germano, que son los grandes modelos inspiradores del Derecho a nivel global. En la región de América Latina, al reconocerse el Pluralismo Jurídico, se aprecia como en el Derecho Indígena son reconocidos los derechos a los animales (León-Guzmán, 2006, pp.185-226, Melo, 2009, Quirola, 2009, Wolmer, 2010, Hermosa Mantilla, 2014). En el Derecho Francés se observa un apego al Derecho Romano, en cuanto a la cosificación de los animales, ocurriendo en este tipo de ordenamiento, lo mismo que en el nuestro, el que, por cierto, deriva directamente de aquel, es decir, existen normas que protegen y se preocupan por el bienestar de aquello que jurídicamente ha sido sindicado como objeto material, lo que ciertamente es contradictorio. El Derecho Germano y el Austriaco, por su raíz no romana, admiten un mayor desapego a la teoría de la cosificación de los seres vivos no humanos, yendo incluso más allá, al establecerse constitucionalmente, como un deber del Estado la obligación de proteger a los animales, al decir de lo señalado por los estudios de Serra (2013, pp.1-9). Por su parte, Zaffaroni (2011) señalaba que, "el constitucionalismo andino dio el gran salto del ambientalismo a la ecología profunda, es decir, a un verdadero ecologismo constitucional. La invocación de la Pachamama va acompañada de la exigencia de su respecto, que se traduce en la regla básica ética del sumak kawsay, que es una expresión quechua que significa buen vivir o pleno vivir y cuyo contenido no es otra cosa que la ética -no la moral individual-que debe regir la acción del estado y conforme a la que también deben relacionarse las personas entre sí y en especial con la naturaleza. No se trata del tradicional bien común reducido o limitado a los humanos, sino del bien de todo lo viviente, incluyendo por supuesto a los humanos, entre los que exige complementariedad y equilibrio, no siendo alcanzable individualmente. [...] Siendo una regla de convivencia que en modo alguno niega la utilización de la naturaleza y ni siquiera de la técnica, sino que exige respeto a 
todo lo humano y no humano, tiene implicancias de todo orden en el plano político y económico y, naturalmente, enfrenta decididamente al suicida festival del mercado encarnado en un capitalismo desenfrenado."

A continuación, se analizará cómo se ha comportado el control público dirigido al bienestar animal por parte de los servidores públicos de la Administración Pública en el ejercicio de sus funciones, por su vínculo con la exigencia de la responsabilidad penal.

\section{EL CONTROL ADMINISTRATIVO DIRIGIDO AL BIENESTAR DE LOS ANIMALES POR LOS SERVIDORES PÚBLICOS}

Una de las técnicas que permiten a la Administración Pública intervenir en la libertad de los particulares y en todo tipo de organizaciones, es la idea de policía administrativa. Si entre los deberes del Estado está el de "evitar realmente los daños y riesgos" al decir de Nieto (1993, p. 29), será preciso dotar a éste de una potestad preventiva y sancionadora. Por ello, parte del trabajo de la Administración Pública consiste en comprobar el cumplimiento del ordenamiento jurídico, sancionar su incumplimiento, y restablecer la legalidad cuando sea posible. La policía administrativa es, por tanto, "aquella actividad de la administración que, en vista de la consecución y el mantenimiento del orden público, se ejercita limitando los derechos de los administrados y, eventualmente, mediante el ejercicio de la coacción sobre los mismos", como lo refiere en sus estudios Entrena Cuesta (1962, p. 804).

Desde el punto de vista teleológico se ha dicho también que la policía administrativa es "el conjunto de medidas utilizadas por la Administración para que el particular ajuste su actividad a un fin de utilidad pública" (Garrido Falla, 1953, p.11). Aunque la doctrina académica no es unánime en el uso del término, y abundan quienes prefieren referirse a la actividad administrativa de limitación de derechos o actividad de ordenación como Parejo Alfonso (1996, p.388), García de Enterría y Fernández Rodríguez (1999, p. 157) o Parada Vázquez (2002, p.380), lo cierto es, con independencia de su denominación, que el Estado tiene importantes poderes de limitación, control y represión.

Una de las técnicas de control administrativo es precisamente la inspección, que está dirigida a velar por el cumplimiento de las normas, como lo señala Rivero (2000, p. 75). La Administración tiene la potestad de inspección, lo que significa que puede ejercer un poder exorbitante para observar y verificar el cumplimiento del ordenamiento. Sin embargo, la legislación española está incorporando progresivamente mecanismos de autocontrol que coadyuvan en las tareas de inspección, por lo que algún autor ha sostenido que se está produciendo un desplazamiento de la policía administrativa por la gestión de riesgos, así lo valida Esteve Pardo (2003, 
pp. 323-346), o la incorporación de la técnica del análisis del riesgo a la actividad administrativa sobre la base de un enfoque preventivo (Recuerda, 2006, pp. 37-38).

Entre las distintas finalidades de la inspección (recaudatoria, de recogida de información, pedagógica, y preventiva), destacada por sus efectos en la esfera de derechos de los particulares, la actividad de prevención. La "amenaza" de una eventual inspección que investigue y compruebe el cumplimiento de las normas es un factor de prevención que será más o menos eficaz en función de diferentes elementos tales como la probabilidad de ser inspeccionado.

Lo hasta aquí analizado, permitirá abordar las conductas antijurídicas vinculadas al derecho de los animales.

\section{EL BIENESTAR DE LOS ANIMALES, LA TIPIFICACIÓN DE CONDUCTAS ANTIJURÍDICAS}

Las causales que son objeto de regulación jurídica en relación a la tipificación de conductas antijurídicas en relación al maltrato y crueldad animal desde el Derecho español, el que se toma como referente por su origen idiomático, desarrollo del Derecho Animal. En este derecho sustantivo aparecen regulaciones en el transporte de animales por carretera en viajes largos, el que sólo puede realizarse previa inspección y aprobación del medio de transporte. Si el transporte de los animales de las especies bovina, ovina, caprina o porcina se va a realizar por vía marítima desde un puerto comunitario hasta una distancia de más de diez millas náuticas solo se podrá realizar previa inspección y aprobación del buque.

Antes de la carga de los animales, los buques que se vayan a utilizar para el transporte deben ser inspeccionados para comprobar que el buque está construido y equipado para el número y tipo de animales que van a transportarse, que los compartimentos destinados a los animales están en buen estado, y que el equipamiento se mantiene en buenas condiciones de funcionamiento. Además, la autoridad competente debe examinar que los animales están en condiciones de proseguir el viaje, que la carga y descarga se efectúan conforme a una serie de reglas, y que no falte el suministro de alimento y agua. Los medios de transporte que se utilicen para viajes largos deben contar con un certificado emitido por la autoridad competente. Con carácter previo, dichos medios tendrán que ser inspeccionados. El inspector deberá comprobar que se cumplen una serie de requisitos relativos al diseño, la construcción y el mantenimiento. Cuando se trate de viajes largos de équidos domésticos y animales domésticos de la especie bovina, ovina, caprina y porcina, los veterinarios oficiales de los puntos de salida y de los puestos de inspección fronterizos deben efectuar controles adicionales. La autoridad competente debe adoptar las medidas necesarias para evitar o reducir al máximo cualquier retraso en el transporte o el sufrimiento de los animales, y en los puestos de inspección, deberá dar prioridad 
al transporte de animales. No puede retenerse ninguna partida de ganado durante el transporte salvo que así lo aconseje el bienestar de los animales o motivos de salud pública. Si la detención es por más de dos horas se tienen que adoptar las medidas necesarias para atender a los animales, y si es necesario, se debe proceder a su descarga a fin de que abreven, coman y descansen.

La regulación de los medicamentos de uso humano y productos sanitarios aborda su investigación clínica, evaluación, autorización, registro, fabricación, elaboración, control de calidad, almacenamiento, distribución, circulación, trazabilidad, comercialización, información y publicidad, importación y exportación, prescripción y dispensación, seguimiento de la relación beneficio-riesgo, así como la ordenación de su uso racional y el procedimiento para, en su caso, la financiación con fondos públicos. Sin embargo, de forma conexa se refiere también al bienestar animal. Así, por ejemplo, los medicamentos veterinarios, aparte de cumplir las garantías generales de calidad, seguridad y eficacia para la salvaguarda de la salud, deben respetar el bienestar de los animales. Se da tal importancia a esta cuestión que la falta de cumplimiento de la normativa sobre bienestar animal puede tener repercusiones en el procedimiento de autorización de un medicamento veterinario (Sessano Goenaga, 2002, Kemelmajer de Carlucci, 2010, pp.1-9, Campos Serena, 2011, pp.1-22).

\section{EL DERECHO PENAL. REGULACIÓN DE LOS DELITOS CONTRA EL MALTRATO ANIMAL EN EL ORDENAMIENTO JURÍDICO CUBANO}

La historia de Cuba, como consecuencia de la transculturación recibida por la colonización española, heredó una fuerte tradición respecto a la violencia animal, reflejada con mayor fuerza en las corridas de toros y peleas de gallos. Las peleas de gallos constituyeron en su tiempo una insignia de la cultura española y criolla, y aún en nuestra época es una actividad cotidiana y aprobada por las autoridades, de gran aceptación por la mayoría de los pobladores nacionales y extranjeros que visitan al país.

La primera fundación creada en la nación para la protección de los animales fue la Sociedad Protectora de Niños, Animales y Plantas, también conocida como Bando de Piedad en 1906. Su objetivo principal era desplegar acciones para proteger y ayudar a niños desamparados, mujeres y ancianos desvalidos y también bestias de tiro, perros, gatos callejeros, seres inermes, victimizados por el hambre y la crueldad.

Con el triunfo de la Revolución en 1959, se aprecia cómo se produjo un cambio significativo en relación a los recursos naturales, que pasan a su vez en virtud de las leyes revolucionarias dictadas, a manos del Estado. Son aprobadas disposiciones 
relativas a la protección de los bosques, el desarrollo de áreas protegidas y la organización de territorios. Dando respuesta al problema forestal en el año de 1959, la Ley n. 239 puso en vigor el Plan de Reforestación del Ejército Rebelde, estableciendo la creación de Parques Nacionales.

Se constata en todo este íter que desde 1969, al crearse el Instituto Nacional de Medicina Veterinaria por la Ley n. 1224, como organismo rector de todas las actividades veterinarias del país, quien entre otras funciones le corresponde la del bienestar animal, el que, en 1976, se adjuntó al Ministerio de la Agricultura, responsabilizándose con las funciones de dicho Instituto. Le corresponden como funciones principales de la institución: organizar, dirigir y controlar el sistema de la sanidad animal en el país, establecer y aplicar las regulaciones para proteger el territorio nacional de la introducción de enfermedades exóticas, los programas de emergencia, prevención y control de las enfermedades de los animales incluyendo las zoonosis, la vigilancia epizootiológica, el diagnóstico de laboratorio, la política de uso y registro de los medicamentos veterinarios, el control higiénico sanitario de los alimentos de origen animal destinados al consumo del hombre y para la alimentación animal, así como organizar y ejecutar la asistencia veterinaria.

En 1975, en el Primer Congreso del Partido Comunista se aprueba la tesis sobre la política científica, donde se determina la necesidad de crear un órgano encargado de atender a los problemas del Medio Ambiente; un año más tarde con la Promulgación de la Constitución de la República se introduce en el artículo 27, la protección de dicho bien jurídico, en dicho artículo se evidencia claramente el objetivo de lograr el desarrollo sostenible, así como una marcada cultura Antropocentrista, centrando dicha protección en función del humano y no del ecosistema en sí, hecho heredado de lo planteado en la Conferencia de Estocolmo de 1972.

En la nación, a partir del reconocimiento de los postulados constitucionales establecidos en los artículos 10, 27 y 69, es el articulo 27 quien consagra la protección ambiental como una función pública del Estado. Toda vez que técnicamente, a la vez que se habilitaron los órganos competentes para que intervengan en la protección ambiental inspirados en el desarrollo sostenible, se ordenó la aplicación de dicha habilitación con el objetivo de "hacer más racional la vida humana y asegurar la supervivencia, el bienestar y la seguridad de las generaciones actuales y futuras" con lo que la solidaridad en términos de equidad inter e intrageneracional, la racionalidad y la sostenibilidad al trascender al texto constitucional cubano.

En 1976, el Consejo de Ministros creó la Comisión Nacional de Protección del Medio Ambiente y Conservación de los Recursos Naturales (COMARNA). Con el segundo Congreso del Partido en 1980, se establece la necesidad de elaborar una legislación adecuada para dar cumplimiento a la política ambiental trazada, lo cual sentó las bases para que, en 1981, la Asamblea Nacional del Poder Popular 
aprobase la Ley n. 33, de Protección del Medio Ambiente y el uso racional de los recursos naturales.

No obstante, hay que señalar que la realidad cubana en torno al trato hacia los animales, está matizada por una serie de factores que confluyen e inciden en que la situación respecto a esta problemática sea precaria. El maltrato hacia ellos puede ser cometido tanto por sujetos comunes como por el personal encargado del manejo, transportación o sacrificio de los mismos. En esta cuerda, en 1994, producto de una nueva reorganización del aparato estatal, con la extinción de COMARNA, sus atribuciones y obligaciones son transferidas al Ministerio de Ciencia, Tecnología y Medio Ambiente (CITMA), cuya función principal consiste en controlar y dirigir la política encaminada a garantizar la protección del Medio Ambiente y el uso racional de los recursos naturales. La principal legislación con respecto al Derecho Ambiental cubano es la Ley n. 81 de 1997 del Medio Ambiente, norma que, debido a los cambios socioeconómicos y en el ámbito ambiental por el que estaba transitando el país durante ese período, incluye disposiciones normativas referidas a las aguas terrestres, suelos, flora, fauna, recursos marinos, recursos agropecuarios y otros.

Se constata como el CITMA, organismo de la Administración Pública, ha ejecutado a través de la función inspectora regulada en la Ley n. 81 de 1997, y ha realizado investigaciones científicas para la protección de biodiversidad de especies protegidas. Aunque hay que significar que existen otros organismos dentro del entramado de la Administración Pública que ejercitan la función inspectiva en la protección ambiental, por su interdisciplinariedad y transdisciplinariedad de esta rama técnica del derecho, realizadas a través de la inspección sanitaria ejecutada por el Ministerio de Salud Pública, el que evalúa el componente ambiental y el respeto de las ordenanzas sanitarias; el Ministerio del Interior en relación a la obediencia de la seguridad laboral; el Ministerio de Economía y Planificación para el control de la política pública destinada a la protección de los animales; el Ministerio de la Agricultura en relación a la política forestal, agraria, y la medicina veterinaria.

Los autores aprecian que, en el ordenamiento jurídico nacional, en relación con los cuerpos jurídicos que trascienden desde el Derecho Ambiental en el tema de la exigencia de responsabilidad, y en especial el Derecho de los Animales en la materia penal, no hay una adecuada unidad, plenitud y coherencia, toda vez que es necesario construir invariantes teóricas y normativas para desde la teoría tributar a la adecuada regulación de los derechos de los animales en Cuba, en atención a autores como Alexy (1997), De Lucas (2009), Atienza (2004) o Bobbio (1995), para lograr el perfeccionamiento del ordenamiento jurídico. Que permita sistematizar de manera adecuada los elementos que definen los derechos de los animales desde el principio de legalidad, para analizar una serie de condicionantes o invariantes que incidan en el conjunto normativo (ordenamiento jurídico) señalado por Santi 
Romano (1963), en atención a la unidad, plenitud y coherencia, del número de disposiciones jurídicas relacionadas con la exigencia de la responsabilidad, en especial de la penal. Con ello el legislador podrá valorar todos estos elementos que le aporte el organismo de la Administración Pública -Ministerio de la Agricultura-, con el proyecto de norma jurídica en la Asamblea Nacional del Poder Popular de la nación, y se decide la aprobación de un cuerpo jurídico que proteja el bienestar animal en Cuba. También se comprueba cómo interviene en todo este control ambiental, el órgano de la Fiscalía General de la República, a tenor del artículo 27 constitucional, para alcanzar el desarrollo sostenible y del artículo 42, de la Ley n. 81 de 1997, al regularse la función especial que posee este órgano de control en relación a la actuación fiscal para la tutela ambiental y el cumplimiento de la juridicidad -artículo 10 constitucional- comprobado con la acción de Verificación Fiscal, establecida en la Ley n. 83 de 1997, de la Fiscalía General de la República.

Tras el análisis del ordenamiento jurídico cubano, se aprecia que en el desarrollo normativo no existe aún una legislación vinculada a la protección jurídica de los animales de manera especial: los documentos regulatorios, bien elaborados técnica y legalmente para otros fines, no se ajustan a las nuevas pautas y directrices preconizadas por la ciencia del bienestar animal desde la Medicina Veterinaria. Los cuerpos jurídicos que hacen alusión al cuidado y protección de la biodiversidad cubana, se aprecian en el Decreto Ley n. 136 de 1993, del patrimonio forestal y la fauna silvestre y el Decreto Ley n. 137 de 1993, de la Medicina Veterinaria; pero estos no protegen de manera adecuada la crueldad y el maltrato animal.

Se pondera que, la protección del medio ambiente y los recursos naturales en la nación en su desarrollo normativo, parte de la Ley n. 81 de 1997, rectorada por el CITMA, es la normativa que posee mayores atisbos en relación con la temática abordada en este artículo, pero aún es insuficiente. A pesar de que el tema del bienestar animal ha tenido un amplio espacio, reflexión y debate, enfocado principalmente a las diferentes manifestaciones de maltrato, crueldad y abuso que se observan a lo largo y ancho del país por parte de las Ciencias Veterinarias y de la actuación de los cuerpos de Inspección Estatal, se valora que no hay una respuesta adecuada con la aplicación del Derecho Administrativo Sancionador a los sujetos infractores; ante su impacto negativo en la calidad de vida y el bienestar de los animales, su repercusión en la Salud Pública y en el bienestar de la población cubana, hoy imponen la necesidad de su juridicidad y de un adecuado control administrativo por parte de la Administración Pública con la aplicación de la función inspectiva (Ramírez Sánchez \& Antúnez Sánchez, 2016).

Todo esto permite concluir que deberán seguirse ejecutando estudios por la Ciencia del Derecho para profundizar en la temática relacionada con la protección de los animales desde la academia y la práctica en las Sociedades Científicas, como un paradigma a resolver por la Administración Pública, que permita el desarrollo 
de una normativa jurídica para contextualizar en el desarrollo social y económico de la nación cubana esta meta, y de esta forma contribuir a decodificar el paradigma del principio de desarrollo sostenible a partir de lo señalado en el artículo 27 constitucional, en el binomio deber-derecho de los sujetos obligados a la juricidad, al decir de autores como Di Cagno (2005), Caraballo Maqueira (2005), Cánovas González (2012), Rey Santos (2013), Antúnez Sánchez (2015).

Se considera la necesidad de estudiar desde la ciencia del Derecho la protección de los animales, toda vez que Cuba aún sigue con un bloqueo económico de una data de más de 50 años, lo que incide en el uso de animales para el traslado de personas y mercancías, donde existen manifestaciones del trato no adecuado y trabajo excesivo de los animales de tracción animal utilizados en el transporte terrestre en las ciudades y pueblos del territorio nacional (caballos, asnos, chivos); otra manifestación son las peleas de perros que se realizan en disimiles sitios donde hay actos de crueldad, agresividad y abusos, se aprecia en el abandono por sus dueños de los perros y gatos los que se convierten en vagabundos en las zonas urbanas con un alto índice poblacional, en acciones de caza, inobservando la juridicidad de especies protegidas para su venta a ciudadanos cubanos o a foráneos que visitan el país y que practican el turismo de naturaleza, el mantener a los animales en condiciones no higiénicas en hogares o sitios públicos, el abandono de animales heridos o enfermos en la vía pública, el uso de animales de trabajo en condiciones de salud desfavorables -enfermos-, las peleas de gallos, la tauromaquia en actividades de rodeo, etc.

Se constata la presentación del primer proyecto de ley presentado en el 2003, pero este que carecía de cuestiones técnicas bien elaboradas por un escaso manejo del tema hasta el momento. El texto fue confeccionado por la Asociación Cubana para la Protección de Animales y Plantas (ANIPLAN). Posteriormente, con el interés de buscar el Bienestar Animal en Cuba, en el 2007 se presentó el segundo proyecto de Ley al Ministerio de la Agricultura, pero de forma similar se negó la presentación a la Asamblea Nacional para su discusión.

Todo ello conspira, a criterio de los autores, con el cumplimiento adecuado de los principios del Derecho Ambiental como son el de legalidad, de prevención, y el de responsabilidad. $O$ expresado de manera diferente, no existe una Policía Administrativa que controle los animales sin permiso ni tenencia legal como mascotas, o los que sirven de guías a ciegos o sordos, para evitar que sean maltratados por sus dueños y que no reciban una adecuada atención médica con la evidencia de su vacunación programada en Clínicas Veterinarias, que no sea controlada de manera científica la natalidad a través de la cirugía para la esterilidad, entre otras conductas antijurídicas, que pudieran tener control administrativo.

El principio de legalidad supone que la Administración sólo puede ejercer las potestades que le sean expresamente atribuidas por la ley. Como exigencia del Estado 
de Derecho este principio implica que nadie puede ser sancionado por acciones $\mathrm{u}$ omisiones que no hayan sido reguladas previamente por el legislador como delitos, faltas o infracciones administrativas, nullum crimen, nulla poena sine lege. Para ello, se toma como ejemplo las regulaciones como referente, que se establecen en el ordenamiento jurídico de España, en atención al idioma y el desarrollo normativo en la protección de los derechos de los animales, de la cual aún hay presencia en la normativa nacional, en cuestiones como:

- El cuidado de los animales en su explotación, transporte, experimentación y sacrificio.

- El sacrificio o muerte de animales en espectáculos públicos fuera de los supuestos expresamente previstos en la normativa aplicable en cada caso o expresa y previamente autorizados por la autoridad competente.

- El incumplimiento de las obligaciones exigidas por las normas de protección animal en cuanto al cuidado y manejo de los animales, cuando concurra la intención de provocar la tortura o muerte de los mismos.

- Utilizar los animales en peleas.

- Utilizar animales en producciones cinematográficas, televisivas, artísticas o publicitarias, incluso con autorización de la autoridad competente, cuando se produzca la muerte de los mismos.

- El incumplimiento de la obligación de aturdimiento previo.

- La realización de un procedimiento sin la autorización previa de la autoridad competente, cuando se utilizan animales incluidos en el apéndice I del Convenio sobre comercio internacional de especies amenazadas de fauna y flora silvestres, CITES.

- Provocar, facilitar o permitir la salida de los animales de experimentación u otros fines científicos del centro o establecimiento, sin autorización por escrito del responsable del mismo, cuando dé lugar a la muerte del animal o cree un riesgo grave para la salud pública.

- Suministrar documentación falsa a los inspectores o a la Administración.

- Utilizar perros o gatos vagabundos en procedimientos.

- Liberación incontrolada y voluntaria de animales de una explotación.

- Las mutilaciones no permitidas a los animales.

- Reutilizar animales en un procedimiento cuando la normativa aplicable no lo permita o conservar con vida un animal utilizado en un procedimiento cuando la normativa aplicable lo prohíba.

- Realizar cualquiera de las actividades reguladas en la ley sin contar con la autorización administrativa o la inscripción registral exigible según las normas de protección animal aplicables. 
- El incumplimiento de las obligaciones exigidas por las normas de protección animal en cuanto al cuidado y manejo de los animales, cuando produzca lesiones permanentes, deformaciones o defectos graves de los mismos.

- La oposición, obstrucción o falta de colaboración con la actuación inspectora y de control de las Administraciones Públicas, cuando se impida o dificulte gravemente su realización.

- El incumplimiento de obligaciones exigidas por las normas de protección animal en cuanto al cuidado y manejo de los animales, siempre que no se produzcan lesiones permanentes, deformidades o defectos graves, o la muerte de los animales.

- El incumplimiento de las obligaciones en cuanto a la forma, métodos y condiciones para el sacrificio o matanza de animales, excepto el aturdimiento, cuando no concurra el supuesto establecido en el artículo 6.3.

- Abandonar a un animal, con el resultado de la ausencia de control sobre el mismo o su efectiva posesión Castro Álvarez (2007), Pocar (2009), De Lucas (2009), García Sáez (2012).

El Derecho administrativo sancionador puede funcionar a criterio de los autores como un muro de contención para determinadas prácticas contra los animales. Sin embargo, consideramos que existen actitudes que se concretan en actos de tal naturaleza abusiva que requieren respuestas más acordes con las exigencias materiales de la sociedad ya que la realidad social es la que condiciona al Derecho y por lo tanto, la necesidad de regular determinadas acciones de los hombres de acuerdo a dicha realidad hace indispensable que nos pronunciemos por la prohibición penal de aquellos conductas lesivas que inciden en el orden social aun cuando los sujetos pasivos de estas sean los animales, seres que al fin y al cabo, sufren y padecen. Todos estos elementos analizados en este epígrafe permitirán realizar el análisis de la normativa penal cubana a la luz de Derecho Animal.

\section{LA NORMATIVA PENAL CUBANA A LA LUZ DEL DERECHO ANIMAL}

El Código penal cubano clasifica las transgresiones según según el bien jurídicamente protegido que es amenazado o lesionado por la conducta criminal. De esta forma, el Derecho Penal asegura por medio de la sanción la protección de los bienes reconocidos por el legislador como dignos de tutela. La protección del medio ambiente, a través de su cuidado, prevención y represión de aquellas conductas que lo dañen, funciona en respuesta de un mandato constitucional que atañe la obligación de todas las personas, tanto naturales como jurídicas, de preservar el medio ambiente y de realizar acciones encaminadas a lograr dicha protección.

Negar la razón de ser al hecho de tipificar las agresiones al ambiente de manera específica, vale decir, de declararlo como bien jurídico y, por ende, como digno de 
tutela penal, implicaría pasar por alto esta obligación legal y constitucional existente aduciendo que cuando el ambiente se protege se hace en función del hombre, por tanto, no se justifica un título "De los delitos contra el ambiente" o una ley especial en el mismo sentido. Este argumento resulta ser muy débil; de aceptarse, concluiríamos por negar la categoría de bien jurídico, por ejemplo, a la propiedad, las buenas costumbres o la administración de justicia, pues cuando se protege a la propiedad, las buenas costumbres o la administración de justicia, siempre se hace en función del hombre, no pudiendo concebirse de otro modo. Y, de toda evidencia, si las categorías antes expuestas, merecen ser protegidas, pues mucho más el ambiente, del cual dependemos. De igual modo al tipificar las conductas agresivas al ambiente y los recursos naturales renovables, no sólo se protegen éstos, sino que se alcanza uno de los principios del Derecho Penal: la seguridad de los ciudadanos acerca de lo ilícito.

El medio ambiente como bien jurídico según se dice en la doctrina se trata de un bien jurídico de carácter supraindividual o colectivo, autónomo y de carácter antropocéntrico. En cuanto que bien jurídico de carácter colectivo, se dice que es múltiple "y el delito en tal sentido pluriofensivo", por lo que se procede a su definición a partir de la enumeración de sus elementos. Así vemos que es un bien jurídico completo o sintético en cuanto aglutinador de otros bienes tradicionales, respecto al que la situación socioeconómica actual ha propiciado la exigencia de configurarlo como un bien específico a defender con autonomía.

Las dificultades en relación a la definición del medio ambiente como bien jurídico radican en el surgimiento de los nuevos procesos de medio ambiente, los cuales introducen "bienes jurídicos nuevos, difusos", pero la tutela de estos nuevos bienes jurídicos, como objetivos de organización política, social, económica, es perfectamente legítima, aunque la víctima no esté perfectamente delimitada en sus contornos (y en ocasiones tampoco el sujeto activo), porque, "el derecho penal no tutela víctimas, sino funciones" traducibles en bienes jurídicos. De lo planteado se aduce que dicha protección se debe realizar en primer lugar en cuanto que el medio ambiente es fundamento existencial del ser humano y, en segundo lugar, en cuanto que es un espacio vital idóneo para el desarrollo de las generaciones venideras. Desde este punto de vista, es decir, desde el momento en que consideremos ciertos valores ambientales como bien (o bienes) jurídico, su propia caracterización como tal ha de llevar implícitamente esa característica social o valiosa para la sociedad. En la medida en que el medio ambiente afecta a las relaciones sociales; sólo en la medida en que es un valor social, puede ser bien jurídico. Si carece de esa cualidad, será otra cosa, pero nunca un bien jurídico susceptible de protección por el derecho penal, lo cual no es el caso.

El desarrollo de la ciencia y la técnica en la nación, ha propiciado que el uso de los recursos naturales se lleve a cabo de una forma desmedida y en tal sentido 
resulten insuficientes los medios para la recuperación de los mismos, conllevando dicha actuación al deterioro del entorno y con ello a una posterior afectación de la vida en general, como se aprecia con lo señalado en la Estrategia Ambiental Nacional, donde se señalan las principales causas de contaminación. Es por ello que resulta necesaria la protección del ambiente desde una óptica más restrictiva, como es la exigencia de la responsabilidad penal.

En Cuba, como se ha dicho, los delitos ambientales son protegidos a partir de la Ley n. 81 de 1997, del Medio Ambiente, la cual remite al Código Penal para la represión de aquellas conductas que de una forma u otra dañen el medio ambiente, dicha inserción pone en evidencia que el Estado reacciona a la realidad de que las vulneraciones al derecho a un ambiente sano, ya no sean de trato exclusivo del campo administrativo, con castigos menores y de indiferente opinión de la población, pues la represión que en esta instancia se ejerce, concluye en la imposición de multas, relegando la reparación del daño a posterior término; cuestión que debido al incesante aumento de las violaciones ambientales han resultado ser insuficientes; por tanto, es preciso pasar del pago de multas hacia una motivación que confluya en el respeto al ambiente en razón de la amenaza penal, refiriéndonos en este caso a la responsabilidad penal por delitos ambientales (Fernández Rubio-Legrá, 1999, Di Cagno, 2003, Soler Del Sol, 2013.

Pero aun materializando dichas acciones, la sociedad necesita de un mecanismo más severo que limite la comisión de actos violentos contra los animales. Se parte de la premisa de que cuando las demás ramas del Derecho se vuelven inoperantes y no alcanzan a resolver los conflictos que se presentan en la vida social, debe entrar a desempeñar su papel el Derecho penal, que aunque es de última ratio por la lesividad de sus normas, pues "... limitar o erradicar la violencia implica aplicar o infligir violencia”, se concreta en la opción plausible para combatir conductas que desvirtúan los valores sociales y fomentan patrones de comportamiento contrarios a las normas de convivencia armónica.

Sin embargo, el Código Penal, no prevé la penalización del llamado delito ambiental -delito ecológico-, solamente plantea algunas conductas antijurídicas lesionadoras del medio asociadas a la protección de la salud, bienes de las personas y la economía nacional, dejando aislada la penalización de otras conductas que no solo abarcan las actividades de contaminación empleando sustancias tóxicas, sino otras que lesionan el medio dentro de las cuales se pueden citar: los delitos contra el Patrimonio Histórico, delitos contra la Ordenación del Territorio, delitos contra los Recursos Naturales, delitos referidos a la protección de la Vida Silvestre, entre otras conductas. Indudablemente, la prevención constituye el medio ideal para proteger el ambiente, pero ello no nos debe llevar a descuidar las medidas represivas, aquellas que intervienen una vez producido el hecho dañoso y, por consiguiente, una vez comprobado que la prevención tuvo fallas. No obstante, el 
papel de las medidas represivas es fundamental, aun cuando sólo fuera porque ellas van a asegurar las medidas preventivas.

Los delitos relacionados con la protección ambiental no responden, según la estructura actual de la norma sustantiva penal a la adecuada protección del medio ambiente como bien jurídico público, pues se le da la categoría de bien jurídico a los Títulos del Código Penal que tratan una objetividad jurídica determinada, y no aparece ninguno con esta señalización; estos aparecen regulados indistintamente a partir de los artículos 185,186, 187, 189, 194, 195, 196, 198, 199, 237, 238, 239, 241 y 242, correspondientes a la Salud Pública como dependiente de la Seguridad Colectiva y la Economía Nacional. Son delitos, en su mayoría, intencionales, de peligro común, con sujetos activos generales y marcos sancionadores relativamente bajos o no graves.

Los autores consideran que los delitos con incidencia ambiental en Cuba se han desarrollado a través de los años con números casi iguales, a partir de que se relacionan en la categoría de delitos pluriofensivos debido a que se cometen conjuntamente con otros delitos que lesionan el bien jurídico perteneciente a la naturaleza como bien público de uso colectivo, pero las normas penales continúan estáticas desde los años 80 del pasado siglo, por tanto, estas figuras delictivas antes señaladas no están completamente a tono con la realidad jurídica y la práctica de la justicia en Sede Penal, necesitadas de renovación y su adecuada actualización a tono con la doctrina penal consultada (Goite Pierre, 1999, Medina Cuenca, 2006).

La Ley n. 62 de 1987, se divide en Parte General y Parte Especial, en este ensayo jurídico se analizará la segunda (Parte Especial) que para su estudio y aplicación se divide en títulos. Sin embargo, estos obedecen a criterios de clasificación distintos a los seguidos en la Parte General. En cada título de la Parte Especial se agrupan las figuras delictivas conforme al objeto del delito, o sea, con arreglo a la relación social que resulta defendida por la norma jurídico-penal por la Ley, aparecen ubicados en el título referente a los delitos cuyo objeto resulta más afín. Empero, la-Parte Especial- de la norma sustantiva penal cubana no aparece el medio ambiente en sus títulos y por ende en sus capítulos o secciones dejando al medio ambiente totalmente desprotegido -como bien jurídico-. No existiendo así una concomitancia entre los preceptos 11, 12 y 13, de la Carta Magna, donde se establece una obligatoriedad tanto para personas naturales como jurídicas, de cuidar y preservar el medio ambiente como bien jurídico colectivo y de los animales, y allí donde fallen los mecanismos administrativos, civiles y otros que puedan existir, se debe contar con la debida protección penal como instrumento coercitivo de última ratio que tiene el Estado para proteger sus bienes. La tipificación de los delitos contra el ambiente, necesariamente encaminará el Derecho Ambiental hacia la satisfacción de sus reales objetivos y, al mismo tiempo, fomentará una concientización más profunda en lo referente a los daños al entorno. Por otra parte, tal promulgación 
no es indispensable sólo por las razones anunciadas, sino por su naturaleza, que escapa a las normas tradicionales. La promulgación de una ley penal de protección al ambiente, y no sanciones aisladas, con objetivos diferentes, con soluciones parciales, en un cuerpo único y un único criterio, resulta necesaria pues servirá de acicate y orientación, así como facilitará la regulación de dicha conducta. Se considera reseñar que, para futuras modificaciones de la normativa jurídica, se deberá atender el tratamiento al bien jurídico de los delitos ambientales en función de su especialización y la delimitación de la responsabilidad penal ambiental de la persona jurídica, pues constituye última ratio para tales conductas detectadas por la auditoría ambiental, como responsabilidad de los sujetos de gestión auditados en el sector estatal cubano.

Dentro de la legislación penal, es necesario reconocer la responsabilidad de la Persona Jurídica, a partir de los cambios que se operan en el nuevo escenario mercantil con la actualización del modelo económico y social, que no es el que operaba en la década del 70 del pasado siglo con una economía centralizada a través de la empresa estatal socialista, donde se defina su concepto, los delitos en que podrá participar como sujeto activo, los mecanismos legales que permitan su detección y enjuiciamiento, y el procedimiento para aplicarse en estos procesos (Medina Cuenca, 2006, Vera Toste, 2008 y Goite Pierre, 2009). En el tráfico mercantil nacional del siglo XXI, se constata como coexisten varios sujetos de gestión económica, como el empresario individual con empresas privadas y las cooperativas no agropecuarias. El régimen sancionador de los delitos con incidencia ambiental se agrupa en la familia de los delitos contra la economía nacional y la salud colectiva en la Ley n. 62 de 1987, resultando necesario ordenarlos en la familia de los delitos contra el medio ambiente y con ello proteger los ecosistemas de la nación cubana en atención a lo regulado en la Ley n. 81 de 1997, que defina la responsabilidad de la Persona Jurídica, lo que deberá constituir parte de esta actualización en la codificación penal.

\section{PAUTAS PARA EL PERFECCIONAMIENTO}

De forma general, se aprecia un despertar en la concientización de la protección de los animales en el proceso de producción de alimentos, no obstante, existen limitaciones en el orden normativo que pueden tratarse teniendo en cuenta las siguientes pautas:

$\checkmark$ El Derecho Animal debe ser concebido como rama con autonomía dentro del Derecho Ambiental.

$\checkmark$ El Derecho Animal debe establecer mecanismos normativos que permitan la obligatoriedad de los procedimientos, técnicas y consideraciones delimitadas por las Ciencias Veterinarias, expresada en una Ley de Protección Animal. 
Las granjas y centros de producción de alimentos animales deben establecer los protocolos y reglamentos internos, de acuerdo al Bienestar Animal, La Ley de Protección Animal y su reglamento.

$\checkmark$ Debe perfeccionarse la función inspectiva en el Derecho Ambiental y su materialización con los servidores públicos de la Administración.

$\checkmark$ Deben criminalizarse conductas que afectan gravemente el bienestar animal y la producción de alimentos y que no están tipificadas en el Código Penal, sobre todo con la responsabilidad penal de personas jurídicas (enfermedades no tratadas, desnutrición animal, etc.)

\section{A MANERA DE CONCLUSIONES}

La doctrina en relación con la regulación del maltrato animal, está dividida en dos posiciones contradictorias: la Teoría de los Derechos animales y la Teoría del Bienestar animal. La más acertada es la Teoría del Bienestar animal en atención a lo señalado en este ensayo jurídico, por apoyar la utilización de los animales a través de métodos que limiten el sufrimiento innecesario.

El Derecho administrativo cubano en relación a la protección de los animales, prima la visión antropocentrista al no existir una reglamentación que incluya el Bienestar de los animales como objetivo principal. El estudio de Derecho comparado de las normas administrativas arrojó que las legislaciones tienden a ser especistas, las medidas a aplicar por los servidores públicos son por lo general, de escasa connotación y los sujetos maltratadores no encuentran en estas normas un límite para su actuar. La aplicación de multas no logra inhibir este tipo de conducta, es una necesidad perentoria acudir a otros mecanismos legales, como es la norma penal. Aunque en los Códigos penales analizados se pudo determinar que los ordenamientos jurídicos no son homogéneos en cuanto a la regulación del maltrato animal, pero la tendencia en relación a las penas es minimalista.

La responsabilidad penal ambiental se concibe como aquella que se deriva de una conducta tipificada como delito, y la misma se concreta en la aplicación de una pena por la acción u omisión dolosa o culposa del autor de una u otra, es estrictamente personal, de interpretación restringida, de irretroactividad vedada, de voluntariedad presunta (una vez demostrada la relación de causalidad entre el ejecutor o inductor y el resultado), y es de orden público.

Es de importancia la regulación de los delitos ambientales en un cuerpo único dentro de la legislación penal, o sea, la reglamentación del ambiente como bien jurídico debido al incremento desmedido de las afectaciones al mismo buscando una mayor represión a estas conductas lesionadoras del entorno, ya que las mismas también afectan ya sea de forma directa o indirecta la vida de los seres humanos. 
Se le estaría dando cumplimiento a un mandato constitucional que nos obliga a todas las personas tanto naturales como jurídicas a preservar el medio ambiente y a realizar acciones encaminadas a lograr dicha protección.

\section{BIBLIOGRAFÍA}

AA. VV. (2012). Direito Ambiental No Século XXI: Efetividade e Desafíos. Sao Paulo: Editorial Classica.

AA. VV. (2011). Retos y tendencias del Derecho Ambiental contemporáneo. La Habana: Editorial ONBC.

AA. VV. (2009). La sostenibilidad, la agroecología y la biodiversidad en Cuba. Principales formas de medición. Cuba: Universidad de Matanzas.

AA. VV. (2007). Temas de Derecho Agrario Cubano. La Habana: Editorial Félix Varela.

AA. VV. (2007). Derecho Ambiental Cubano. La Habana: Editorial Félix Varela. AA. VV. (2005). Derecho Penal Especial, 2 Tomos. La Habana: Editorial Félix Varela. AA.VV. (2002). Estudios de Derecho Administrativo cubano. La Habana: Editorial Félix Varela.

AA.VV. (2004). Temas de Derecho Administrativo cubano, 2 Tomos, $1^{a}$ edición. La Habana: Editorial Félix Varela.

AA. VV. (2002). Derecho Penal contemporáneo. Colombia: Editorial Jurídico Gerardo Oñati.

Afonso Da Silva, J. (2009). Derecho Ambiental Constitucional. Brasil: Editorial Método. Aguiló, J. (2008). Sobre Derecho y argumentación. Palma: Editorial Lleonard Muntaner. Alenza García, J. (2007). Potestad de inspección. Revista Actualidad Jurídica Ambiental, España.

Alexy, R. (1997). Teoría de la argumentación jurídica. Madrid: Editorial Shurkand. Altamirano Vergara, P. (2012). Derechos de los animales: una reivindicación contemporánea. Tesis doctoral. Universidad Austral, Chile.

Alterini, A. (2009). ¿Derechos de los animales? Revista Jurídica, 13, Argentina, 60-68. Antúnez Sánchez, A. (2016). El Derecho Animal. Una aproximación jurídica desde el Derecho Ambiental cubano. Revista Letras Jurídicas, 22, México.

Antúnez Sánchez, A. (2013). Marco teórico legal del delito penal ambiental, tratamiento en el Derecho cubano. Revista Letras Jurídicas, 16, México.

Arana García, E. (2013). Animales de compañía y Administración local. Revista Derecho del Medio Ambiente y Administración Local, 727-753.

Aranda, A. (2001). Ética en experimentación con animales de laboratorio. Manual de Bioética, $1^{2}$ edición. Barcelona: Editorial Ariel.

Aristóteles (1988). Acerca del Alma. Madrid: Editorial Gredos. 
Avellaneda Vásquez, D. \& Peñuela Navarrete, M. (2010). El maltrato animal. Una reflexión desde la sostenibilidad y las tradiciones culturales. Revista de Ingeniería de Recursos Naturales y del Ambiente, 9, España.

Atienza, M. (2009). Razón práctica y legislación. Revista Mexicana de estudios Parlamentarios, I, México.

Atienza, M. (2004). Argumentación y legislación. Madrid: Editorial Thomson Civitas. Ayes Ametller, G. (2003). Medio Ambiente: impacto y desarrollo. La Habana: Editorial Científico Técnica.

Barros, P. (2001). El Discurso del Método de Rene Descartes. Sitio de Libros Maravillosos. Recuperado de: http://www.librosmaravillosos.com

Bellido Jara, C. \& Gómez Brown, H. (2007). Los Animales y su situación frente al Derecho. Revista de Derecho de Valdivia, Chile.

Bellorio Clabot, D. (2013). El nuevo paradigma ambiental y jurídico. Revista Iberoamericana de Derecho Ambiental y Recursos Naturales, Argentina.

Bellorio Clabot, D. (2004). Tratado de Derecho Ambiental, $1{ }^{\underline{a}}$ edición. Buenos Aires: Editorial Astrea.

Beltrao, A. (2011). Direito Ambiental, $3^{\text {ra }}$ edición. Brasil: Editorial Método.

Bermejo Vera, J. (1998). La Administración Inspectora. Revista de Administración Pública, 147,1-20.

Betancor Rodríguez, A. (2001). Instituciones de Derecho Ambiental. Madrid: Editorial La Ley.

Bifani, P. (1999). Medio ambiente y desarrollo sostenible, $4^{\text {ta }}$ edición. Madrid: Iepala. Blanco Lozano, C. (1997). El delito ecológico. Manual operativo, $1^{\underline{a}}$ edición. Madrid: Editorial Montecorvo.

Bobbio, N. (1995. Teoría de Ordenamiento Jurídico, $6^{\text {ta }}$ edición. Brasil: Editorial Universidade de Brasilia.

Botassi, C. (1997). Derecho Administrativo Ambiental. La Plata: Editorial Platense.

Brañes Ballesteros, R. (1997). La fundación del Derecho Ambiental Latinoamericano. México: PNUMA.

Brels, S. (2012). La protección del bienestar animal: una preocupación universal que se debe considerar globalmente y seriamente en el Derecho Internacional. Revista de Derecho Animal, España, 1-6.

Bustamante Alsina, J. (1995). Derecho Ambiental, fundamentación y normativa, $1^{\mathrm{a}}$ edición. Buenos Aires: Editorial Abeledo Perrot.

Caferrata, N. (2013) Análisis del marco regulatorio en los países de América Latina y el Caribe. Economía verde en el contexto del desarrollo sostenible y erradicación de la pobreza. México: PNUMA.

Caferrata, N. (2003). Introducción al Derecho Ambiental. México: Editorial PNUMA-SEMARNAT. 
Campos Serena, O. (2011). Más allá de una concepción instrumental del valor de los animales: la irracionalidad del paradigma humanista. Revista de Filosofía, 2, 1-22.

Cánovas González, D. (2012). Necesidades y potencialidades del Derecho Ambiental cubano. La Habana: CITMA.

Cánovas González, D. (2011). Estudios sobre Derecho del Ambiente. Caracas: Editorial Hermanos Vadell.

Cañizares Abeledo, F. (1970). Teoría del Estado y del Derecho. La Habana: Editorial Universitaria.

Capo Martí, M. (2012). Maltrato y crueldad en animales. Revista Bienestar Animal, España, 1-6.

Caraballo Maqueira, L. (2002). El Derecho Ambiental, un instrumento de gestión eficaz de conservación de la diversidad biológica. Tesis doctoral. La Habana: Universidad de La Habana.

Caraballo Maqueira, L. (2014). El Derecho Ambiental. Realidades y esperanzas. La Habana: Editorial Acuario.

Carreras, J. (1982). Historia del Estado y el Derecho en Cuba. La Habana: Editorial Pueblo y Educación.

Castro Álvarez, M. (2007). Algunas reflexiones sobre la legislación internacional y española en materia de animales de compañía. Revista de Bioética y Derecho, $11,1-10$.

Cuello Calón, E. (1951). Derecho Penal, Tomo I, Parte General, 10ª Edición. Barcelona: Editorial Bosch.

De Besa Antunes, P. (2010). Direito Ambiental. Brasil: Editorial Lumen Juris.

De Lora, P. (2003). Justicia para los animales. La ética más allá de la humanidad. Madrid: Editorial Alianza.

De Lucas, F. (2009). En el bicentenario de Darwin. ¿Derechos de los animales no humanos? La barrera de la dignidad. Revista Teoría y Derecho, 6, 6-19.

De Lucas, J. (2006). Introducción a la teoría del Derecho. La Habana: Editorial Félix Varela.

De Medeiros García, L. (2010). Derecho Ambiental Constitucional. El derecho interno ambiental a partir de la protección constitucional, $2^{\text {da }}$ edición. Brasil: Editorial Jus Podivm.

De Miguel, I. (2009). Derechos para los animales. Revista Dilemata, 1, 1-17.

Del Rio Sanz, I. (2007). Controversia: Derecho Animal, A Parte Rei. Revista Filosófica, 53.

Descartes, R. (1995). Discurso del Método. Meditaciones físicas. Madrid: Editorial Espasa.

Di Cagno, V. (2005). La protección del medio ambiente en Cuba. La Habana: Editorial Ciencias Sociales. 
Di Cagno, V. (2003). Análisis comparado de la Ley cubana n. 81 del Medio Ambiente. Revista Jurídica, 8.

Di Trindade Amado, F. (2011). Derecho Ambiental Esquematizado, $2^{\text {da }}$ edición. Brasil: Editorial Método.

Diaz Candia, K. (2013). Maltrato animal: un delito con pena desapercibida. Tesis de Maestría. Chile: Universidad Andrés Bello.

Díaz Ocampo, E. \& Antúnez Sánchez, A. (2017). El Derecho Vivo y el ordenamiento jurídico ecuatoriano. Revista Pensamiento Penal, Argentina.

Doménech Pascual, G. (2004). Bienestar animal contra derechos fundamentales. Barcelona: Editorial Atelier.

Entrena Cuesta, R. (1962). Límites de la actividad de policía municipal. REVL, 5.

Escartín, G. (2012). Dies años de observtori de bioética y dret. Revista Bioética y Derecho, 24.

Esteve Pardo, J. (2008). Derecho del medio ambiente. Madrid: Editorial Marcial Pons.

Esteve Pardo, J. (2003). De la policía administrativa a la gestión de riesgo. REDA, 119.

Estrada Celsi, E. (2008). Bienestar animal: hacia un nuevo paradigma bioético. Revista CES Medicina Veterinaria y Zootecnia, 1, 53-60.

Fernández Bulté, J., Carreras Cuevas D. \& Yañez García, R. (1995). Manual de Derecho Romano. La Habana: Editorial Pueblo y Educación.

Fernández Ramos, S. (2012). La inspección ambiental. Revista Medio Ambiente y Administración Local, 1-26.

Fernández Ramos, S. (2000). La inspección en el marco del control de la aplicación del Derecho Ambiental. Revista Derecho Ambiental, 24.

Fernández Rubio-Legrá, Á. (1999). Ley No. 81 de 1997, del Medio Ambiente. En más de 150 preguntas y respuestas. La Habana: Editorial Ministerio de Justicia.

Ferrajoli, L. (2001). Los fundamentos de los derechos fundamentales. Madrid: Editorial Trotta.

Ferrara, F. (1929). Teoría de las personas jurídicas. Madrid: Editorial Reus.

Fix-Zamudio, H. (2010). Los derechos humanos y su protección jurídica en Latinoamérica. Revista Ciencias Jurídicas, UNAM, México D. F.

Foy Valencia, P. (2012). La Constitución y el animal, ensayo jurídico. Lima: Universidad de Lima.

Francione, G. (2009). Animales, ¿propiedad o personas? Revista de Teoría y Derecho, 6, 30-59.

Franciskovic Ingunza, B. (2013). Protección jurídica y respeto al animal: Una perspectiva a nivel de las constituciones de Europa y Latinoamérica. Revista de la Facultad de Derecho de la Universidad Femenina del Sagrado Corazón-Unifé, 8. Franciskovic Ingunza, B. (2012). Los animales desde una perspectiva del Derecho. Son realmente objetos de Derecho o requieren de una nueva categorización. 
Revista de la Facultad de Derecho de la Universidad Femenina del Sagrado Corazón-Unifé, 8, 1-34.

Hammerstein, D. (2007). Diez Pasos hacia una política de protección animal. Decálogo por el Derecho de los Animales. Revista Europa en Verde, Alemania. Hart, H. (1999). Teoría del Derecho, $2^{\text {da }}$ edición. Buenos Aires: Editorial Abeledo Perrot.

Hart, H. (1974). ¿Existen derechos naturales?, Filosofía Política. México: Editorial Fondo Cultura Económica.

Hava García, E. (2011). La protección del bienestar animal a través del Derecho Penal. Revista Estudios Penales y Criminológicos, 31.

Hermosa Mantilla, H. (2014). De los derechos colectivos de los pueblos indígenas al neo constitucionalismo Andino. Quito: Editorial Adya-Yala.

Hernández Pozo, I. (2005a). El Derecho Penal ambiental en Cuba. La Habana: Agencia Medio Ambiente, Dirección Jurídica CITMA.

Hernández Pozo, I. (2005b). Importancia de la protección penal del medio ambiente. Revista electrónica de la Agencia de Medio Ambiente, 8, CITMA, La Habana.

Hernández Torres, V. (2007). Marco institucional ambiental. Derecho Ambiental cubano. La Habana: Editorial Félix Varela.

Humboldt, A. (1884). Ensayo de una descripción física del mundo. Madrid: Editorial Gaspar y Roig.

García Fernández, J. \& Rey Santos, O. (2005). Foros de negociación e instrumentos jurídicos internacionales en materia de medio ambiente y desarrollo sostenible. La Habana: Editorial Acuario.

García Sáez, J. (2012). ¿Pueden los animales ser titulares de derechos? Algunos argumentos desde una teoría garantista del Derecho. Revista catalana de Dret Ambiental, 2, 1-12.

García Ureta, A. (2016) Potestad inspectora y medio ambiente: Derecho de la Unión Europea y algunos datos sobre las Comunidades Autónomas. Revista Actualidad Jurídica Ambiental, 54, 1-36.

Garita Navarro, J. (2009). Comentarios sobre Responsabilidad Objetiva del Estado. Análisis Jurisprudencial. Apuntes de Derecho Administrativo, tomo II. San José: Editorial ISOLMA.

Garrido Falla, F. (1953). La evolución del concepto jurídico de policía y la teoría de las sanciones administrativas. RAP, 11.

Goite Pierre, M. (2012). Las consecuencias jurídicas derivadas del delito y una mirada a la persona jurídica desde Cuba y España. Valencia: Editorial Tirant lo Blanch.

Goite Pierre, M. (1999). La responsabilidad de las personas jurídicas en el Derecho Penal. Revista Cubana de Derecho, 14.

Gomes Canotilho, J. (1998). Introducción al derecho del medio ambiente. Portugal: Editorial Universidad Abierta. 
González Novo, T. (1998). Cuba, su medio ambiente después del medio milenio. La Habana: Editorial Científico-Técnica.

Kelsen, H. (1992). Compendio de Teoría General del Estado. México: Editorial Colofón. Kemelmajer de Carlucci, A. (2010). La categoría jurídica "sujeto/objeto" y su insuficiencia respecto de los animales. Especial referencia a los animales usados en laboratorios. Revista de Bioética y Derecho, 17, 1-8.

Klöepfer, M. (2012). El Derecho Ambiental en Alemania. Revista de Derecho Ambiental. Berlín: Universidad Humboldt.

Kolbert, E. (2015). La sexta extinción. Una historia nada natural. México: Editorial Crítica.

Leff, E. (2001). Los derechos del ser colectivo y la reapropiación social de la naturaleza: a guisa de prólogo. En Justicia Ambiental: construcción y defensa de los Nuevos Derechos Ambientales, Culturales y Colectivos en América Latina Red de Formación Ambiental, Serie Foros y Debates Ambientales Numero 1. PNUMA /UNAM.

León-Guzmán, M. (2006). El bienestar animal en las legislaciones de América Latina. Revista de Ciencias Veterinarias, 24, 185-226.

Leyton, F. (2000). Problemas bioéticos de la experimentación con animales no humanos. Madrid: Editorial Gredos.

Lorenzetti, R. L. (2007). El paradigma ambiental, Tomo I, Perspectivas sobre Derecho Ambiental y de la Sustentabilidad. Argentina: Editorial EUCASA.

López de la Vieja, M. (2005). Derechos de los animales, deberes de los humanos. Revista Isegoria, 32.

Lozano Cutanda, B. (2015). Tratado de Derecho Ambiental, $1^{\text {a }}$ edición. Madrid: Editorial CEF.

Marcheco Acuña, B. (2015). Constitución y justicia administrativa en Cuba. ¿Una relación imposible? Revista Estudios Constitucionales, 2, Chile.

Márquez Piñeiro, R. (2003). Teoría de la antijuricidad. México: Instituto de Investigaciones Jurídicas-UNAM.

Martín Blanco, S. (2012). Reflexiones morales sobre los animales en la filosofía de Martha Nussbaum. Revista Bioética y Derecho, 25, 59-72.

Martín Mateo, R. (1998). Tratado de Derecho Ambiental, 2ª edición. Madrid: Editorial Trivium.

Martín-Retortillo Báquer, L. (2006). Derechos fundamentales y medio ambiente. Madrid: Universidad Complutense de Madrid.

Masri, Al-Hafiz Basheer A. (1987). Preocupación Islámica por animales. Athene Trust. Matfield, M. (2002). Animal experimentation: the continuing debate. Nature Reviews, I, 149-152.

Matos Hidalgo, L. \& Antúnez Sánchez, A. (2017) Los delitos ambientales en Cuba. Necesidad del cambio (en prensa). 
McCormack Bequer, M. (2007). Temas de Derecho Agrario Cubano, 2 Tomos. La Habana: Editorial Félix Varela.

Medina Cuenca, A. (2006). Leyes penales (Comentadas, actualizadas y concordadas). La Habana: Universidad de La Habana.

Meier, H. (2003). El Derecho Ambiental y el nuevo milenio. Caracas: Editorial Homero. Melo, M. (2009). Los derechos de la Naturaleza en la nueva Constitución ecuatoriana. Derechos de la Naturaleza. El futuro es ahora. Quito: Editorial Abya-Yala.

Méndez López, J. (2003). La constitución política. Papel que desempeña en la protección del Derecho Ambiental. Revista Santiago. Santiago de Cuba.

Mora Ruiz, M. (2007). La gestión ambiental compartida. Función Pública y Mercado. Madrid: Editorial Lex Nova.

Morales Lamberti, A. (2008). Estudios de Derecho Ambiental. Argentina: Instituto de Derecho Ambiental y de la Energía.

Moreno Plata, M. (2010). Génesis, evolución y tendencias del paradigma del desarrollo sostenible. México: Editorial Porrúa.

Mosterín, J. (1995). Los derechos de los animales. Madrid: Editorial Debate.

Nieto, A. (1999). Algunas precisiones sobre el concepto de policía. Barcelona: Editorial Universidad Autónoma de Barcelona.

Nieto, A. (1993). Derecho administrativo sancionador. Madrid: Editorial Tecnos.

Parada Vázquez, R. (2002). Derecho Administrativo. Madrid: Editorial Marcial Pons.

Parejo Alfonso, L. (2013). El derecho al medio ambiente y la actuación de la Administración Pública. Cizur Menor: Editorial Aranzadi.

Pérez Monguió, J. (2005). Configuración y posición de los animales ante el Derecho: el estatuto jurídico de los animales. Revista Animales de Compañía, Editorial Bosch, España.

Pigreti, E. (2007). Ambiente y Sociedad. El bien común planetario. Buenos Aires: Editorial Lajouane.

Pigretti, E. (2003). Derecho Ambiental Profundizado. Buenos Aires: Editorial La Ley. Pocar, V. (2009). Derechos de los animales y derechos humanos. Revista Teoría y Derecho, 6, 20-28.

Prieto Valdés, M. (2003). El ordenamiento jurídico cubano. La Habana: Editorial Félix Varela.

Prieur, M. (2003). Derecho del Medio Ambiente, 5a edición. París: Editorial Dalloz-Sirey.

Queipo Cruz, R. (2000). Protección Penal del medio ambiente. La Habana: Dirección Jurídica CITMA.

Quiala Armenteros, Y. (2011). La inspección estatal ambiental en Cuba. Tendencias actuales de la Inspección Ambiental en los países del primer mundo. Revista cubana de Derecho Ambiental, 5.

Quirola Suárez, D. (2009). Sumak Kaway. Hacia un nuevo pacto social en armonía con la naturaleza. Ecuador: Editorial Abya-Yala. 
Quirós Pírez, R. (2005). Manual de Derecho Penal, Tomo I. La Habana: Editorial Félix Varela.

Quirós Pírez, R. (1987). Introducción a la teoría del Derecho Penal. La Habana: Editorial Ciencias Sociales.

Rabal Méndez, P. (2014). Los derechos de los animales desde la óptica del Bioderecho: ¿Utopía o realidad? Revista Bioderecho, 1,1-12.

Ramírez Sánchez, A. \& Rizo Pérez, N. (2017). La exigencia de responsabilidad patrimonial de la Administración Pública en Cuba. Limitaciones en su acceso a la justicia administrativa (en prensa).

Ramírez Sánchez, A. \& Antúnez Sánchez, A. (2015). La responsabilidad administrativa derivada de la inspección estatal sanitaria en Cuba. Una mirada a su régimen jurídico sancionador desde la lucha contra el dengue. Revista electrónica Derecho y Cambio Social, Perú.

Rebollo Puig, M. (2011). La actividad inspectora. Madrid: Editorial Iustel.

Rebollo Puig, M. (2010). Policía administrativa y sanciones administrativas. Revista Ius Publicium, España.

Rebollo Puig, M. (1999). La peculiaridad de la policía administrativa y su singular adaptación al principio de legalidad. Revista Vasca de Administración Pública, 54.

Regan, T. (2006). Jaulas vacías: el desafío de los derechos de los animales. Barcelona: Fundación Altarriba.

Rey Santos, O. (2013). Fundamentos del Derecho Ambiental. La Habana: Editorial CIABO.

Rey Santos, O. (2008). El Desarrollo del Constitucionalismo Ambiental en Latinoamérica. PNUMA.

Rincón Higuera, E. (2011). Algunas razones filosóficas contra el maltrato animal ¿Por qué los animales humanos deberíamos considerar moralmente a los animales no humanos? Revista Polisemia, 11, México.

Rivero, R. (2000). El Estado vigilante. Madrid: Editorial Tecnos.

Rodríguez García, M. (2010). El bien jurídico medio ambiente en el Derecho Penal. Antología de la Revista cubana de Derecho Ambiental, CITMA, La Habana.

Rojas, H., Stuardo L. \& Benavides, D. (2005). Políticas y prácticas de bienestar animal en los países de América: estudio preliminar. Revista Ciencia, Técnica y Epizootiología, 549-565.

Rosa Moreno, J. (2000). El Derecho ambiental en Latinoamérica. Madrid: Editorial McGraw-Hill.

Sánchez Savedra, K. (2013). El bienestar de los animales doméstico y la prevención del delito. Revista Observatorio de la Violencia, 5, Panamá.

Santi, R. (1963). El ordenamiento jurídico. Madrid: Editorial Instituto de Estudios Políticos. 
Santiago Fernández, L. (2013). El maltrato animal desde un punto de vista criminológico. Revista de Derecho y Cambio Social, Perú.

Serra, J. (2013). Derecho animal en la legislación de la República Argentina. Revista de Derecho Animal,1-9.

Sessano Goenaga, J. (2002). La protección penal del ambiente. Revista ECPC, España, 1-34.

Silveira Da Rocha Sampaio, R. (2011). Direito Ambiental. Brasil: Editorial Elservier. Singer, P. (1999). Liberación Animal. Madrid: Editorial Trotta.

Soler Del Sol, A. (2013). El Derecho al alcance de todos, Ley No.81 Ley del Medio Ambiente. La Habana: Editorial ONBC.

Soriano Garcia, J. \& Brufao Curiel, P. (2010). Claves de Derecho Ambiental, 3 Tomos, $1^{\text {a }}$ edición. Madrid: Editorial Iustel.

Soro Mateo, B. (2012). Nuevos retos del derecho ambiental desde la perspectiva del bioderecho. Especial referencia a los derechos de los animales y de las futuras generaciones. Revista Via Iuris, 13, Colombia.

Stuardo, L. (2014). El Bienestar Animal en Animales de Granja I: la situación en Chile. Boletin Veterinario Oficial, Chile.

Toledano Cordero, D. (2012). El derecho al disfrute de un medio ambiente sano. Reconocimiento constitucional y formas de garantía. La Habana: Universidad de La Habana.

Trujillo Cabrera, J. (2009). El derecho de los animales en Colombia. Revista Republicana, 7, 69-82.

Valls, M. (2008). Derecho Ambiental, 5ª edición. Buenos Aires: Editorial Abeledo Perrot.

Vera Toste, Y. (2008). Temas Penales. La Habana: Editorial Unijuris.

Viamontes Guilbeaux, E. (2012). Derecho y Medio Ambiente: protección de la salud y la calidad de vida. La Habana: Editorial Pablo de la Torriente Grau.

Villavella Armengol, C. (2011). Los derechos humanos y el medio ambiente su tratamiento en el Derecho Constitucional comparado. Revista electrónica de estudios jurídicos CUBALEX, UNJC, 1-10.

Wolf, Ú. (2001). La ética y los animales. Frankfurt: Editorial ZDF.

Wolkmer, A. (2010). Pluralismo crítico y nuevo constitucionalismo en América Latina, $3^{\text {a }}$ edición. Brasil: Editorial Alfa-Omega.

Zaffaroni, E. (2011). La Pachamama y el humano. Buenos Aires: Editorial Madres de la Plaza de Mayo.

Zaffaroni, E. (1988). Tratado de Derecho Penal, 4 tomos. Buenos Aires: Editorial Eliar. 